\title{
One-Day Prediction of Biometeorological Conditions in a Mediterranean Urban Environment Using Artificial Neural Networks Modeling
}

\author{
K. P. Moustris, ${ }^{1}$ P. T. Nastos, ${ }^{2}$ and A. G. Paliatsos ${ }^{3}$ \\ ${ }^{1}$ Department of Mechanical Engineering, Technological Educational Institute of Piraeus, 250 Thivon and P. Ralli Street, \\ 12244 Aegaleo, Greece \\ ${ }^{2}$ Laboratory of Climatology and Atmospheric Environment, Faculty of Geology and Geoenvironment, \\ University of Athens, Panepistimiopolis, 15784 Athens, Greece \\ ${ }^{3}$ General Department of Mathematics, Technological Educational Institute of Piraeus, 250 Thivon and P. Ralli Street, \\ 12244 Aegaleo, Greece
}

Correspondence should be addressed to K. P. Moustris; kmoustris@yahoo.gr

Received 13 June 2013; Revised 11 August 2013; Accepted 5 September 2013

Academic Editor: Andreas Matzarakis

Copyright (C) 2013 K. P. Moustris et al. This is an open access article distributed under the Creative Commons Attribution License, which permits unrestricted use, distribution, and reproduction in any medium, provided the original work is properly cited.

\begin{abstract}
The present study, deals with the 24-hour prognosis of the outdoor biometeorological conditions in an urban monitoring site within the Greater Athens area, Greece. For this purpose, artificial neural networks (ANNs) modelling techniques are applied in order to predict the maximum and the minimum value of the physiologically equivalent temperature (PET) one day ahead as well as the persistence of the hours with extreme human biometeorological conditions. The findings of the analysis showed that extreme heat stress appears to be $10.0 \%$ of the examined hours within the warm period of the year, against extreme cold stress for $22.8 \%$ of the hours during the cold period of the year. Finally, human thermal comfort sensation accounts for $81.8 \%$ of the hours during the year. Concerning the PET prognosis, ANNs have a remarkable forecasting ability to predict the extreme daily PET values one day ahead, as well as the persistence of extreme conditions during the day, at a significant statistical level of $P<0.01$.
\end{abstract}

\section{Introduction}

The impact of climate and prevailing weather on human thermal comfort discomfort is almost obvious. Environmental conditions affect the heat balance between the human body and the environment and they are the source of possible discomfort conditions. In particular, during the summer period, extreme meteorological conditions have a direct impact on energy consumption of buildings for airconditioning purposes [1]. It has been reported as an increase of about $800 \%$ in annual purchases of air-conditioning units ever since, due to the serious heat waves observed in Greece during 1987-1989 [2].

Human thermal comfort or discomfort conditions may be assessed through a large number of theoretical and empirical indices requiring usually a larger or smaller number of input microclimate parameters such as air temperature, wind speed, and air humidity [4-6]. An important issue, in terms of human health risk assessment, is to predict the microclimate and the associated human thermal comfortdiscomfort conditions in the urban environment. Despite the existence of various microclimate models, there are only a few models that are able to deal with human thermal comfort estimations, for example, the RayMan model $[7,8]$ and the Envi-Met model [9]. These models may be used efficiently in both estimating and predicting human thermal comfort conditions in the urban environment [10-13].

The present study deals with the application of artificial neural networks (ANNs), an alternative modeling technique against common modeling efforts for the evaluation and the prognosis of human thermal comfort conditions in the urban environment. During the last decade, there has been an increasing use of ANNs, in various aspects of the atmospheric environment studies [14-20]. Despite this increasing use 
of ANNs and their advantages (generalization properties, capability of handling high dimensional data, and nonlinearities), the number of ANNs model applications in problems related to bioclimatic aspects of human health is, however, still limited (e.g., [21, 22]), whereas in the case of the urban environment studies, those focus only on the microclimate patterns [23]. Specifically, during the last decade, only few researches around the world started to apply the artificial neural networks modeling in order to predict the human thermal comfort-discomfort levels for different purposes.

Gao and Bai [24] proposed an artificial neural network model for the prediction of bioclimatic conditions by the use of back-propagation neural network, giving good results. Wong et al. [25] investigated the predictability of clothing sensory comfort from psychological perceptions by using a feed-forward back-propagation network in an artificial neural network (ANN) system. Results, showing a good correlation between predicted and actual comfort ratings with a significance of $P<0.01$ for all of the five developed models, indicated that overall comfort performance is predictable with neural networks, particularly models with log sigmoid hidden neurons and pure linear output neurons. Ji et al. [26] examined the possibility of using ANNs to model the relationship between the thermal environmental factors and the residents' thermal reaction in order to predict the environmental thermal comfort. The test results showed that the ANN model had higher precision in prediction than the traditional method-linear regression under steady conditions. Further, under unsteady conditions, the model can also be correctly used to predict the change of the residents' thermal reaction avoiding dealing with the complicated nonlinear relation, while using the regression method. Atthajariyakul and Leephakpreeda [27] presented a practical approach to determine human thermal comfort quantitatively via neural computing. The results showed good agreement between the thermal comfort index calculated from the neural network model in real time and those calculated from the conventional PMV model. Liu et al. [28] examined the relation between the main influencing factors (such as temperature, relative humidity, air velocity, mean radiant temperature, air pressure, and clothing insulation) and human thermal sensation, using ANN. Moreover, backpropagation (BP) neural network evaluation model of human thermal comfort was put forward under low pressure environment and learning algorithm of network was given. Liu et al. [28] concluded that the prediction of network model is closely consistent with experimental results.

Finally, regarding Greece and the prognosis of human thermal comfort-discomfort levels using ANNs models, Mihalakakou et al. [23] applied an intelligent "data-driven" method (ANN) for investigating, analyzing, and quantifying the urban heat island phenomenon in the major Athens region, where hourly ambient air-temperature data are recorded at twenty-three stations. The results were tested with extensive sets of nontraining measurements and it was found that they corresponded well to the real values. Moustris et al. and Vouterakos et al. [29-31] developed ANNs in order to forecast the human thermal comfort-discomfort levels within the Greater Athens Area (GAA), Greece, as well as the number of consecutive hours of thermal discomfort for the next day. Results in all cases showed that ANNs have a good ability to forecast one day ahead the values of the thermal indices used.

The growth of the city of Athens in the last decades and the phenomenon of urbanization obviously have led to the creation of a microclimate with explicit effects on human thermal comfort-discomfort. The knowledge of human thermal comfortdiscomfort levels, predicted for the next days, is very important for suitable actions in order to protect public health [29-31]. The aim of this work is the prognosis of the biometeorological conditions, expressed by the physiologically equivalent temperature (PET), one day ahead within the GAA urban environment, using ANNs modeling techniques.

\section{Data and Methodology}

2.1. The Monitoring Site. The Greek capital city of Athens is located in an area of about $450 \mathrm{~km}^{2}$ with a complex topography within the Greater Athens Area-basin. According to the census of 2011, about the $40 \%$ of Greece's population lives in the Greater Athens Area (GAA). During the last decades and due to continued population growth, there was an extremely large and rapid spatial and residential growth of the GAA. This development led, according to many scientists, to the heat island effect [32-35]. This phenomenon leads to the creation of microclimates resulting in the configuration of different humans thermal comfort-discomfort conditions even between adjacent regions [32-36].

For the estimation of human thermal comfort-discomfort levels, the physiologically equivalent temperature (PET) in an hourly base was calculated using the RayMan model. Specifically, hourly values of air temperature $\left({ }^{\circ} \mathrm{C}\right)$, wind speed $(\mathrm{m} / \mathrm{s})$, relative humidity $(\%)$, and global solar irradiation $\left(\mathrm{W} / \mathrm{m}^{2}\right)$ covering the period 15/06/2005-31/12/2011 (57,384 hours) were used. These data concern the location of Galatsi (GAL) and have been recorded by the Hydrological Observatory of Athens (HOA) operated by the National Technical University of Athens [37]. Figure 1 depicts the monitoring site within the GAA. The monitoring station is sited within the Galatsi water treatment plant installations of the Water Supply and Sewerage Company of Athens (WSSCA). Data completeness of the examined location-monitoring site is found about $98.8 \%$.

2.2. Physiologically Equivalent Temperature. The PET is based on the Munich Energy balance Model for Individuals (MEMI), which describes the thermal conditions of the human body in a physiologically relevant way [38]. PET is defined as the air temperature at which, in a typical indoor setting (without wind and solar radiation), the heat budget of the human body is balanced with the same core and skin temperature under the complex outdoor conditions to be assessed [39, 40]. Table 1 presents the different stress levels and human thermal sensations according to PET value.

For biometeorological purposes, the height of $1.1 \mathrm{~m}$ is considered as the mean gravity center of the human body [7]. In order to calculate the hourly values of PET, using 


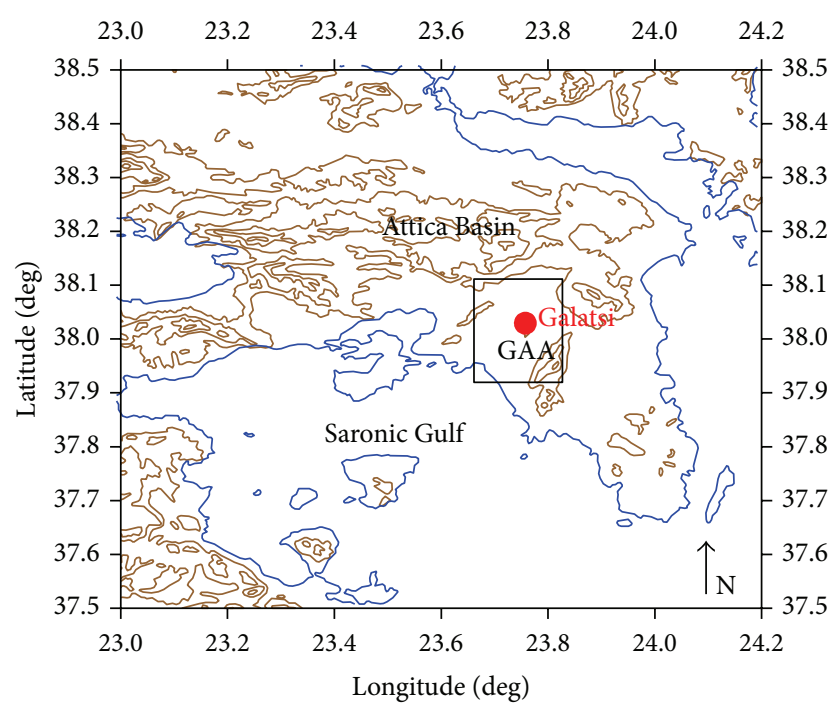

Figure 1: The Greater Athens Area (GAA) along with the examined monitoring site of Galatsi.

TABLE 1: Physiologically equivalent temperature (PET) for different grades of thermal sensation and physiological stress on human beings (during standard conditions: heat transfer resistance of clothing: $0.9 \mathrm{clo}$, internal heat production: $80 \mathrm{~W}$ ) [41].

\begin{tabular}{lcc}
\hline PET $\left({ }^{\circ} \mathrm{C}\right)$ & Thermal sensation & Physiological stress level \\
\hline$<4$ & Very cold & Extreme cold stress \\
8 & Cold & Strong cold stress \\
13 & Cool & Moderate cold stress \\
18 & Slightly cool & Slight cold stress \\
23 & Comfortable & No thermal stress \\
29 & Slightly warm & Slight heat stress \\
35 & Warm & Moderate heat stress \\
41 & Hot & Strong heat stress \\
$>41$ & Very hot & Extreme heat stress \\
\hline
\end{tabular}

the RayMan model, the hourly values of wind speed at $1.1 \mathrm{~m}$ above the ground are necessary. The available wind speed values (56,704 hourly values) derived from an anemometer's recordings, which is mounted on the top of a meteorological mast at a height of $10.0 \mathrm{~m}$ above the ground. The meteorological mast is located inside the water treatment plant installations of the WSSCA. It is a flat area without vigorous and high obstacles 150 200 $\mathrm{m}$ around the meteorological mast approximately. Figure 2 depicts, (Google Maps-Google Earth), the monitoring site inside the WSSCA area.

For that purpose, the measured hourly values of wind speed at $10.0 \mathrm{~m}$ above the ground level had to be recalculated at the high of $1.1 \mathrm{~m}$ above the ground level. This parameterization assumes a logarithmic vertical wind profile as it is described in (1) $[42,43]$ :

$$
u(z)=u_{\mathrm{ref}} \cdot \frac{\ln \left(z / z_{0}\right)}{\ln \left(z_{\mathrm{ref}} / z_{0}\right)},
$$

where $u(z)$ is the wind speed at height $(z)$ above the ground level, $\left(z_{0}\right)$ is the aerodynamic roughness length of the surface

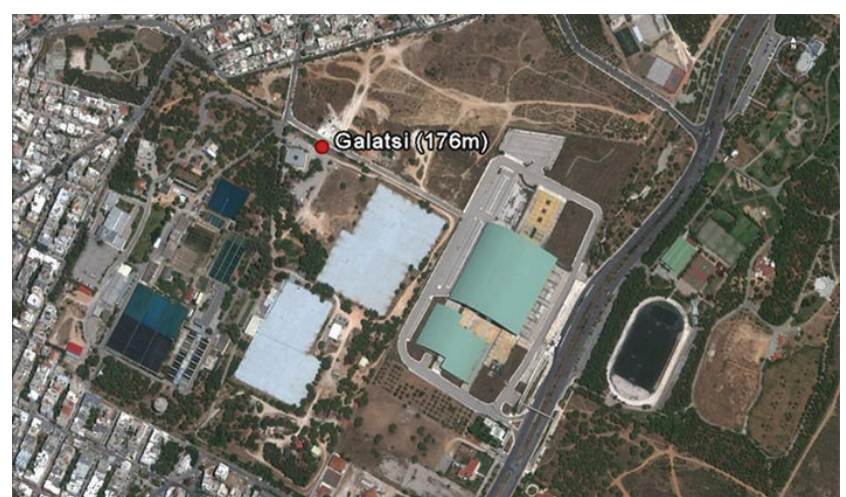

FIGURE 2: Map of the examined monitoring site of Galatsi with its altitude above sea level (from Google Maps-Google Earth).

in meters, and $u_{\text {ref }}$ is the measured wind speed by the anemometer at the $\left(z_{\text {ref }}\right)$ height above the ground level. In our case, $z=1.1 \mathrm{~m}$ and $z_{\text {ref }}=10.0 \mathrm{~m}$. The aerodynamic roughness length of the surface for the given monitoring site was taken as $z_{0}=0.03 \mathrm{~m}$ [44].

Finally, using the hourly values of the air temperature, air relative humidity, wind speed at $1.1 \mathrm{~m}$ above the ground, and the corresponding hourly values of global solar irradiance, the hourly values of PET were calculated.

2.3. Artificial Neural Networks. Artificial neural networks are a branch of artificial intelligence developed in the 1950s aiming at imitating the biological brain architecture. They are an approach to the description of functioning of human nervous system through mathematical functions. Typical ANNs use very simple models of neurons. These artificial neurons models retain only very rough characteristics of biological neurons of the human brain [45]. ANNs are parallel distributed systems made of many interconnected nonlinear processing elements (PEs), called artificial neurons [46]. A renewal of scientific interest has grown exponentially since the last decade, mainly due to the availability of appropriate hardware that has made them convenient for fast data analysis and information processing [47].

During the last two decades, more and more scientists around the world have apply ANNs modeling in many different scientific fields. ANNs have a lot of applications in many sectors such as

(i) pattern classification applications,

(ii) control, time series, estimation, prediction, and prognosis,

(iii) optimization,

(iv) environmental applications,

(v) engineering applications,

(vi) financial and commercial applications,

(vii) medical diagnosis,

(viii) management and marketing applications,

(ix) energy cost prediction. 
2.3.1. Multilayer Perceptron and Feed-Forward ANNs. The Multilayer Perceptron (MLP) is the most commonly used type of ANNs. Its structure consists of processing elements (PEs) and connections [48]. PEs, which are called neurons, are arranged in layers. The first layer is the input layer, one or more hidden layers follow and the final layer is the output layer. An input layer serves as buffer that distributes input signals to the next layer, which is a hidden layer. Each neuron of the hidden layer communicates with all the neurons of the next hidden layer, if any, having in each connection a typical weight factor. So, each unit-artificial neuron in the hidden layer sums its input, processes it with a transfer function, and distributes the result to the output layer. It is also possible that there are several hidden layers connected in the same fashion. The units-artificial neurons in the output layer compute their output in a similar manner. Finally, the signal reaches the output layer, where the output value from the ANN is compared to the target value and an error is estimated. Thus, the values of weight factors are amended appropriately and the training cycle is repeated until the error is acceptable, depending on the application. Since data flow within the artificial neural network from a layer to the next one without any return path, such kinds of ANNs are defined as feedforward ANNs. The structure of a feed-forward Multilayer Perceptron artificial neural network can be represented as in Figure 3.

2.3.2. Feed-Forward ANNs Training and the Back-Propagation Training Algorithm. The training-learning process of ANNs can be far from the ensemble optimum in some cases, and the problem can be solved only with a very good database, the best choice of the input configuration for training, or using most powerful learning algorithms [47].

The back-propagation learning algorithm consists of two steps of computation: a forward pass and a backward pass. In the forward pass, an input pattern vector is applied to the sensory nodes of the network, that is, to the units in the input layer. The signals from the input layer are propagated to the units in the first layer and each unit produces an output. The outputs of these units are propagated to the units in the subsequent layers and this process continues until, finally, the signals reach the output layer, where the actual response of the network to the input vector is obtained (Figure 3).

During the forward pass, the synaptic weights of the network are fixed. During the backward pass, on the other hand, the synaptic weights are all adjusted in accordance with an error signal, which is propagated backward through the network against the direction of synaptic connections.

The mathematical analysis of the algorithm is well described by Viotti et al. [47]. It is worthwhile noting that a network architecture having just one hidden layer and activation functions arranged as described above, constitutes a universal predictor and it can theoretically approximate any continuous function to any degree of accuracy. In practice, such degree of flexibility is not achievable because parameters must be estimated from sample data, which are both finite and noisy [49].

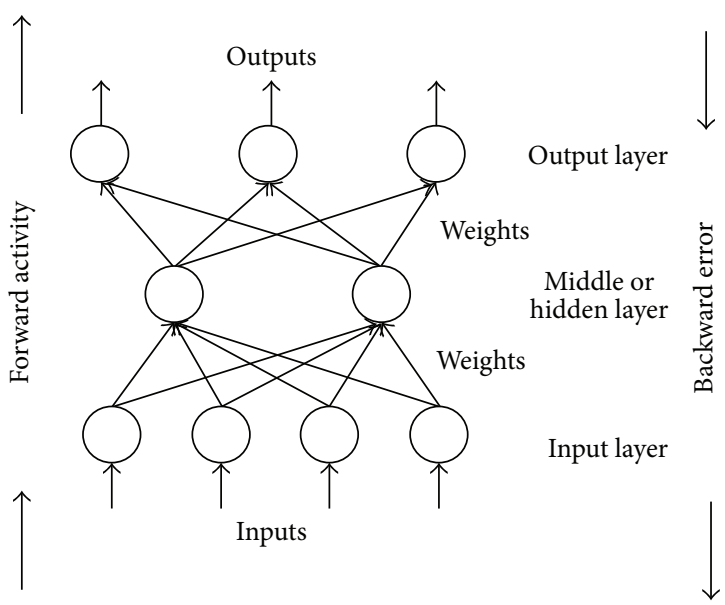

FIgURE 3: Typical MLP feed-forward artificial neural network structure [3].

The ANNs work on a matrix containing more patterns. Particularly, the patterns represent the rows while the variables are the columns. This data set is a sample. To be more precise, giving the ANN three different subsets of the available sample, we can get the forecasting model; the three subsets concern the training, the validation and the test subsets. These subsets are briefly described as follows:

(i) training subset, the group of data with which we traineducate the network according to the gradient descent for the error function algorithm, in order to reach the best fitting of the nonlinear function representing the phenomenon;

(ii) validation subset, the group of data, given to the network still in the learning phase, by which the error evaluation is verified, in order to update the best thresholds and weights effectively. Also, the cross validation phase during the model training is used to avoid the models' overtraining. If the model is overtrained, then memorize the problem instead to find a reliable solution;

(iii) test subset, one or more sets of new and unknown data for the ANN, which are used to evaluate ANN generalization, that is, to evaluate whether the model has effectively approximated the general function representative of the phenomenon, instead of learning the parameters uniquely.

2.4. Architecture Structure of the Developed ANNs Models. Applying the RayMan model, the hourly values of PET were calculated covering the examined period 15/06/2005$31 / 12 / 2011$. Then, the daily maximum and minimum PET values from the 24 hourly values were extracted. Further, the numbers of hours during the day where PET is greater than $41.0^{\circ} \mathrm{C}$ or less than $4.0^{\circ} \mathrm{C}$ (Table 1 ) were estimated.

Two different ANN models were developed. The first, ANN no. 1, was trained to forecast 24 hours ahead the daily maximum and minimum PET value, as well as the number of extreme heat stress hours (PET $>41.0^{\circ} \mathrm{C}$ ) during the next 
day, for the warm period of the year (May-September) [36]. The second ANN model, ANN no. 2, was trained to forecast 24 hours ahead the daily maximum and the minimum PET value, as well as the number of the extreme cold stress hours $\left(\mathrm{PET}<4.0^{\circ} \mathrm{C}\right)$ during the next day, for the cold period of the year (October-April) [36].

In order to estimate the optimal number of previous days that should be taken into account for the appropriate ANNs training, it is important to formulate an appropriate data set and decide how many days prior to the forecasted day should be included in the training data set. For that purpose, the daily maximum and minimum PET values for the studied period have been organized in a superposed epoch analysis (SPEA) illustrations and are depicted in Figure 4 [50, 51].

The "zero" day (D-0) represents the mean daily maximum or minimum PET values for the warm and the cold period of the year, respectively, when an "exceedance" day (PET $>41.0^{\circ} \mathrm{C}$ or PET $<4.0^{\circ} \mathrm{C}$ ) occurred in the monitoring site, Galatsi. The other days, named as D-1, D-2, and so forth, represent the mean value of the daily maximum or minimum PET values $1,2,3,4,5,6,7$, and 8 days before the exceedance day, respectively. In a same manner, the days named $\mathrm{D}+1$, $\mathrm{D}+2$, and so forth, represent the mean value of the daily maximum or minimum PET values 1, 2, 3, 4, 5, 6, 7, and 8 days after the exceedance day, respectively.

The significance of differences between two sample means was investigated applying the $t$-statistic, in other words, the difference of two-means test [52]. This test requires that we calculate two means and compare them to see if one is greater than the other. Results showed that there is a significant increase of mean daily PET values three days before the "zero" day, $t_{(0.05,1024)} \geq 1.960$, and $t_{(0.05,1330)} \geq 1.960$ for the warm and the cold period of the year, respectively, at a significant statistical level of $P<0.05$.

The above results are also depicted in Figure 4, which shows that during the warm period of the year (upper graph), there is a significant increase of daily maximum PET values three days before the "zero" day. The same conclusion is extracted for the cold period of the year (lower graph). It seems that three days before the "zero" day, the daily minimum PET value is reduced.

In other words, when an "exceedance" day $\left(\mathrm{PET}>41.0^{\circ} \mathrm{C}\right.$ or PET $<4.0^{\circ} \mathrm{C}$ ) occurs, there is a significant trend of the daily maximum and minimum values three days earlier. Furthermore, in both warm and cold periods of the year, it appears that the phenomenon is smoothed out three to four days after the onset of the "exceedance" day.

Taking into consideration the SPEA analysis, the appropriate training data set was created, including data concerning the three days, prior to the forecasted day. Initially, the available data were divided in two data files. The first concerns the warm period of the year (May-September) and the second the cold period of the year (October-April). Two different prognostic ANN models were developed, ANN no. 1 for the warm period of the year and ANN no. 2 model for the cold period of the year. In both cases, the available data sets were divided into two subsets. The first subset included data from the period 2005 to 2010 and used for training the ANN model. A portion of this subset (20\%) was used

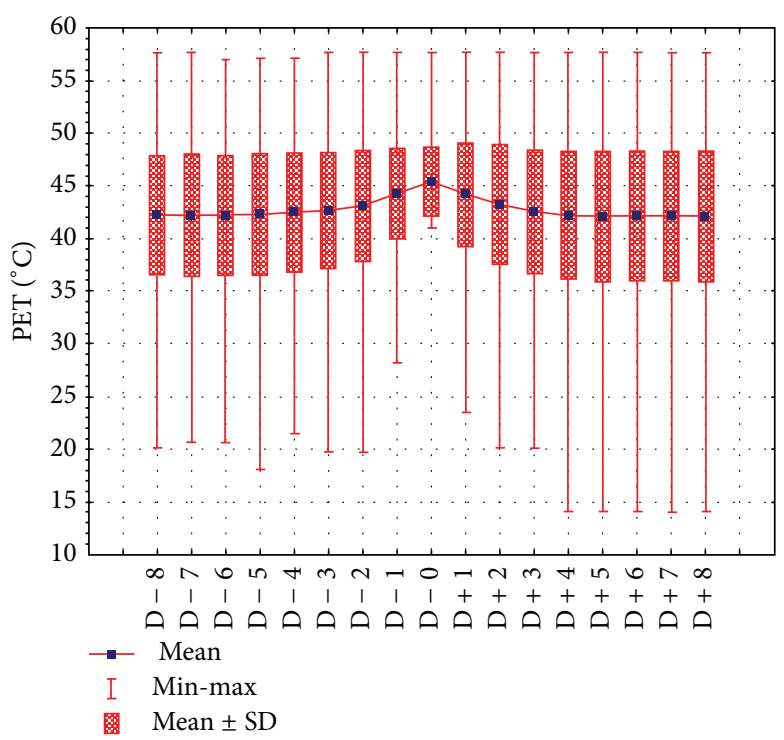

(a)

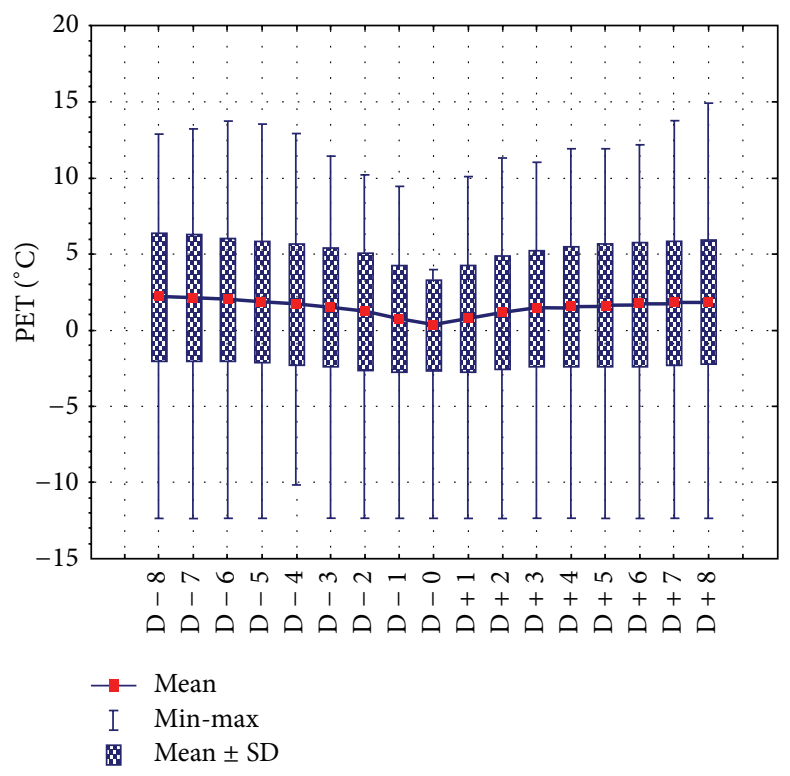

(b)

FIGURE 4: Superposed epoch analysis during the warm period of the year (upper graph) and during the cold period of the year (lower graph).

for cross validation during the training process. The second subset included data for 2011 and was used as the testing set for the evaluation of the developed ANN no. 1 and ANN no. 2 models.

Table 2 presents the input PEs and the outputs targets for the developed ANN no. 1 and ANN no. 2 forecasting models respectively. The two developed models are feed forward MLP ANNs. They consist of one input layer with $21 \mathrm{PEs}$, one hidden layer with $4 \mathrm{PEs}$ (hidden neurons) and one output layer with 3 PEs. Also, they have 4 PEs (hidden neurons) in the hidden layer. The transfer function in both ANN no. 1 and ANN no. 2 is the hyperbolic tangent function, and the learning rule in both models is the momentum [31]. The best ANNs structure 
TABLE 2: The input PEs and the output target for the developed ANN no. 1 and ANN no. 2 forecasting models, respectively.

\begin{tabular}{ll}
\hline Input Layer (PEs) & $\begin{array}{l}\text { Output layer } \\
\text { (targets values) }\end{array}$ \\
\hline The number of the month $(1,2,3, \ldots, 12)$ & \\
The maximum daily air temperature for each of the three previous & \\
days & $\begin{array}{l}\text { The maximum and the minimum daily value of PET of the } \\
\text { next day, as well as the number of hours during the next day } \\
\text { with PET }>41.0^{\circ} \mathrm{C}(\mathrm{ANN} \text { no. } 1) \text { or PET }<4.0^{\circ} \mathrm{C}(\mathrm{ANN} \text { no. } 2)\end{array}$ \\
The minimum daily air temperature for each of the three previous & \\
The maximum daily PET value for each of the three previous days & \\
The minimum daily PET value for each of the three previous days & \\
The number of hours with PET $>41.0^{\circ} \mathrm{C}$ (ANN no. 1$)$ for each of & \\
the three previous days or the number of hours with PET $<4.0^{\circ} \mathrm{C}$ & \\
(ANN no. 2) for each of the three previous days & \\
The persistence factor $(\mathrm{PF})$ for each of the three previous days & \\
The maximum (ANN no. 1 ) and the minimum (ANN no. 2) air & \\
temperature of the next day (the forecasted day) &
\end{tabular}

was selected based on a set of exploratory experiments. The aforementioned architecture structure of both ANN no. 1 and ANN no. 2 was selected after the trial-and-error method [53-56].

The persistence factor (PF), which is mentioned in Table 2, is an integer number. The PF is representing the number of consecutive exceedance days (persistence) where the $\mathrm{PET}$ value is greater than $41.0^{\circ} \mathrm{C}$ (warm period of the year) or less than $4.0^{\circ} \mathrm{C}$ (cold period of the year). For example, $\mathrm{PF}=5$ means that the given day is the fifth consecutive exceedance day, and PF $=6$ means that the given day is the sixth consecutive exceedance day and so on. According to the statistical treatment of the available data, it was found that during the warm period of the year, PF takes values ranging between 1 and 37. This means that 37 consecutive days with daily maximum PET greater than $41.0^{\circ} \mathrm{C}$ (extreme heat stress) were observed at least one time. During the cold period of the year, $\mathrm{PF}$ takes values ranging between 1 and 45 , meaning that 45 consecutive days with daily minimum PET less than $4.0^{\circ} \mathrm{C}$ (extreme cold stress) were observed at least once.

2.5. Statistical Performance Indices. In order to evaluate the results and the predicting performance of the developed models, statistical indices such as the root mean square error (RMSE), the mean bias error (MBE), the coefficient of determination $\left(R^{2}\right)$, and the index of agreement (IA) were used. The coefficient of determination $\left(R^{2}\right)$ provides information about the percentage of the variance that the model is able to explain $[57,58]$. The RMSE is a commonly used measure of the differences between the predicted values by a predictable model and the real observed values. The RMSE is used as a single measure that indicates the ability of the model to predict and has the same units as the predicted value. The RMSE is always positive and a zero value is ideal. The MBE provides information on the longterm performance. A low MBE is desirable. Ideally, a zero value of MBE should be obtained. A positive value gives the average amount of overestimation in the calculated values while a negative value underestimates. The coefficient of determination $\left(R^{2}\right)$ is used in cases of statistical models, whose main purpose is the forecast of future outcomes on the basis of other related information. It is the proportion of the variability in a data set that is accounted for, by the statistical model. It provides a measure of how well future outcomes are likely to be predicted by the model. The coefficient values range from zero to one $\left(0 \leq R^{2} \leq 1\right)$. The closer the value is to one, the better and more accurate the prediction is. The index of agreement is a dimensionless measure with values between zero and one $(0 \leq \mathrm{IA} \leq 1)$. The IA gives information about how close the predicted values are to the observed ones. When IA $=0$, there is no agreement between prediction and observation, while IA $=1$ denotes a perfect agreement between prediction and observation.

The accuracy of the proposed prognostic models to predict the "exceedances" days was assessed by using appropriate statistical indices such as the true predicted rate (TPR), the false positive rate (FPR), the false alarm rate (FAR), and the Success Index (SI) [58]. The true predicted rate (TPR) represents the fraction of correct predictions over total exceedances with values from $0.0 \%$ to $100.0 \%$ and a perfect score equals $100.0 \%$. False positive rate (FPR) represents the fraction of false predictions over total nonexceedances with values from $0.0 \%$ to $100.0 \%$ and a perfect score equals $0.0 \%$. False alarm rate (FAR) represents the fraction of false predictions over total exceedances with values from $0.0 \%$ to $100.0 \%$ and a perfect score equals $0.0 \%$. Finally, SI represents the fraction of correct predictions over total predictions with values from $0.0 \%$ to $100.0 \%$ and a perfect score equals $100.0 \%$.

\section{Results and Discussion}

Initially, the hourly values of PET during the examined period 15/6/2005-31/12/2005 were calculated applying the RayMan model. Figure 5 depicts the time series of hourly PET values, along with extreme heat $\left(\mathrm{PET}>41^{\circ} \mathrm{C}\right)$ and cold stress $(\mathrm{PET}<$ $4^{\circ} \mathrm{C}$ ) thresholds, for the period 15/06/2005-31/12/2011.

According to the statistical treatment data analysis and Figure 5, during the warm period of the year, PET $>41.0^{\circ} \mathrm{C}$ (extreme heat stress) appeared in $10.0 \%$ of the examined 


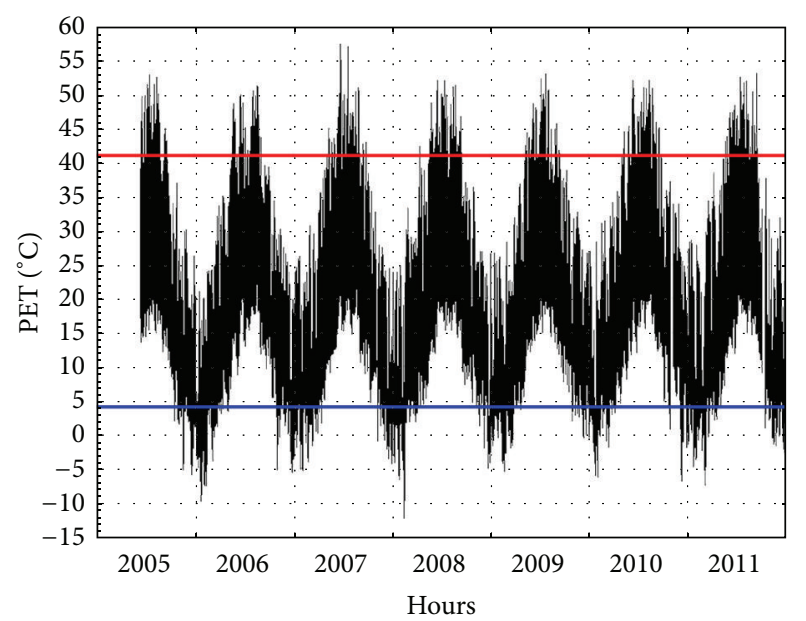

Extreme heat stress

_ Extreme cold stress

FIgure 5: The time series of hourly PET values along with extreme heat $\left(\mathrm{PET}>41^{\circ} \mathrm{C}\right)$ and cold stress $\left(\mathrm{PET}<4^{\circ} \mathrm{C}\right)$ thresholds, for the period 15/06/2005-31/12/2011.

hours $(2,449$ of the 24,609 available hours) present, against $22.8 \%$ of the hours during the cold period of the year $(7,320$ of the 32,095 available hours) with PET $<4.0^{\circ} \mathrm{C}$ (extreme cold stress). Finally, a comfort human thermal sensation appeared in $81.8 \%$ of the hours during the years. This indicates that in general, the bioclimatic conditions in the examined monitoring site could be characterized as human healthy comfort conditions.

As mentioned above, the whole data set was divided into two subsets. The first subset concerns the warm period of the year (May-September) and the second one the cold period of the year (October-April). Further below, the results with respect to the warm and cold period of the year are presented and discussed separately.

3.1. Warm Period of the Year (May-September). The data set of the year 2011 was absolutely unknown to the trained ANN model ANN no. 1. Thus, the model was then fed with the appropriate data in order to forecast 24 hours ahead the daily maximum and minimum PET value, as well as the number of hours during the next day when PET is greater than $41.0^{\circ} \mathrm{C}$ (extreme heat stress). Then, the forecasted values were compared with the observed ones.

Figure 6 depicts the observed versus the predicted daily maximum PET values (a), the scatter plot between the observed versus the predicted daily maximum PET values (b), the differences between the observed and the predicted daily maximum PET values (c), and the histogram with the distribution of the absolute differences between the observed and the predicted daily maximum PET values (d). Further, Figure 7 illustrates the same as Figure 6, but with respect to daily minimum PET values. Table 3 presents the values of the statistical indices used for the evaluation of the forecasting ability of the developed ANN no. 1 model.

According to Figures 6 and 7 and Table 3, the developed ANN no. 1 prognostic model presents a very good forecasting
TABLE 3: Statistical indices for the evaluation of the forecasting ability of the developed ANN no. 1 forecasting model. One day ahead prognosis. Warm period of 2011.

\begin{tabular}{lcccc}
\hline & RMSE & MBE & $R^{2}$ & IA \\
\hline Maximum PET value $\left({ }^{\circ} \mathrm{C}\right)$ & $2.9^{\circ} \mathrm{C}$ & $-0.5^{\circ} \mathrm{C}$ & 0.831 & 0.950 \\
Minimum PET value $\left({ }^{\circ} \mathrm{C}\right)$ & $1.2^{\circ} \mathrm{C}$ & $-0.2^{\circ} \mathrm{C}$ & 0.910 & 0.975 \\
Hours with PET $>41.0^{\circ} \mathrm{C}$ & $1.3 \mathrm{hrs}$ & $-0.3 \mathrm{hrs}$ & 0.796 & 0.938 \\
\hline
\end{tabular}

ability. Specifically, concerning, on one hand, the prediction of the daily maximum PET value, the coefficient of determination equals $R^{2}=0.831$, which means that the model is able to explain $83.1 \%$ of the variability of the daily maximum PET 24 hours ahead. On the other hand, $R^{2}=0.910$ with respect to the prediction of the daily minimum PET value, meaning that the model is able to explain $91.0 \%$ of the variability of the daily minimum PET, 24 hours ahead. Besides, $70.0 \%$ of the absolute differences between the observed and predicted daily maximum $\mathrm{PET}$ values range between $-3.0^{\circ} \mathrm{C}$ and $+3.0^{\circ} \mathrm{C}$, against $98.0 \%$ of the absolute differences between the observed and predicted daily minimum PET values. The same conclusions can be derived concerning the prognosis of the number of the hours during the next day when PET is greater than $41.0^{\circ} \mathrm{C}$. Figure 8 presents the observed versus the predicted hours with PET $>41.0^{\circ} \mathrm{C}$ (a), the scatter plot between the observed and predicted hours with PET > $41.0^{\circ} \mathrm{C}(\mathrm{b})$, the differences between the observed and the predicted hours with $\mathrm{PET}>41.0^{\circ} \mathrm{C}(\mathrm{c})$, and the histogram with the distribution of the absolute differences between the observed and the predicted hours with $\mathrm{PET}>41.0^{\circ} \mathrm{C}(\mathrm{d})$. The coefficient of determination equals $R^{2}=0.796$, meaning that the developed model is able to explain $79.6 \%$ of the variability of the hours with extreme heat stress one day ahead. Finally, $96.0 \%$ of the absolute differences between the observed and the predicted hours with PET $>41.0^{\circ} \mathrm{C}$, range between -3.0 hours and +3.0 hours. All the aforementioned indicate that the developed ANN no. 1 prognostic model, after its appropriate training phase, presents a very satisfactory forecasting ability at a significant statistical level of $P<0.01$.

Table 4 presents the values of the statistical indices for the evaluation of the forecasting ability of the model in order to predict correctly the exceedances days, in other words, the days with daily maximum PET greater than $41.0^{\circ} \mathrm{C}$ (extreme heat stress). Concerning the ability of the model to forecast whether the next day is going to be a day with extreme heat stress sensation (exceedance day) and according to Table 4, the true predicted rate is $\mathrm{TPR}=85.9 \%$, which indicates that the fraction of the correct predictions over total exceedances is forecasted by the model at a rate of $85.9 \%$. Also, FPR $=4.0 \%$ which means that the fraction of false predictions over total nonexceedances is quite small. Furthermore, FAR $=4.3 \%$, meaning that the fraction of false predictions over total exceedances is very small. Finally, SI $=90.8 \%$, which indicates that the fraction of correct predictions over total predictions is about $90.8 \%$. In other words, the developed ANN no. 1 model is able to forecast at a rate of $90.8 \%$ whether the next day is going to be an exceedance day or not. As far as the hours with extreme heat stress $\left(\mathrm{PET}>41.0^{\circ} \mathrm{C}\right)$, one day ahead, are 


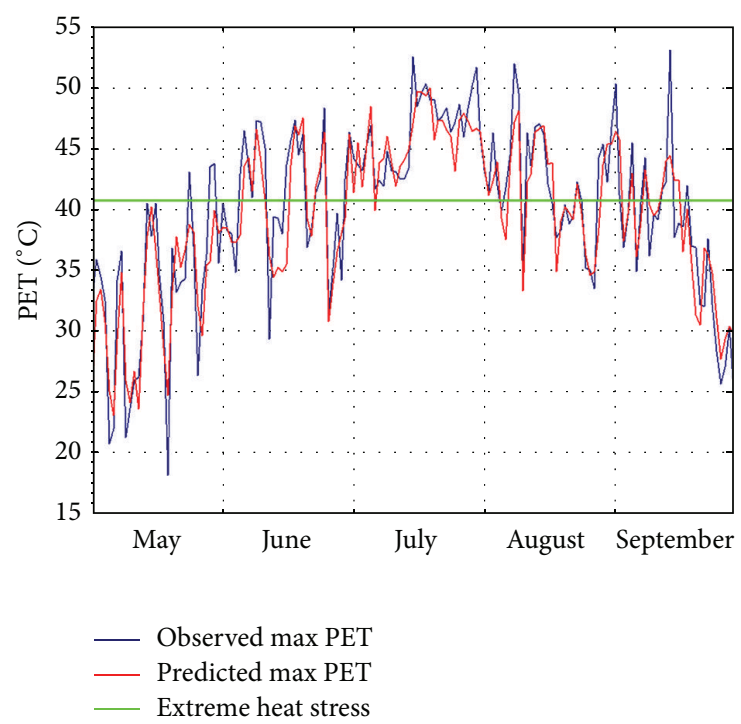

(a)

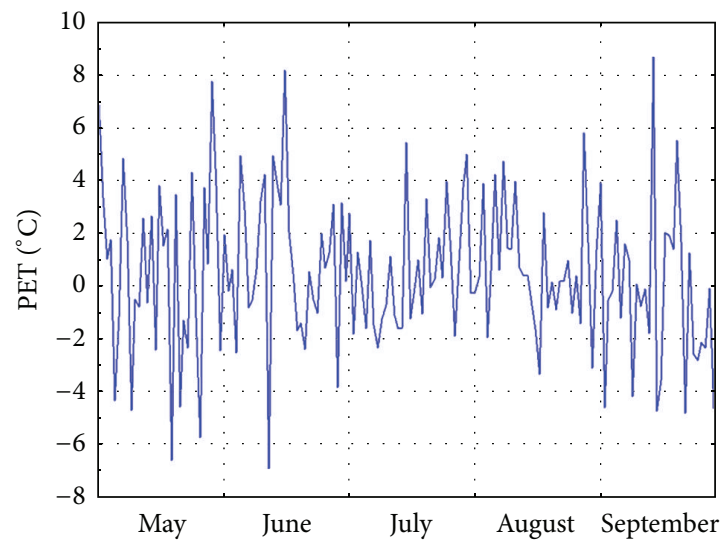

(c)

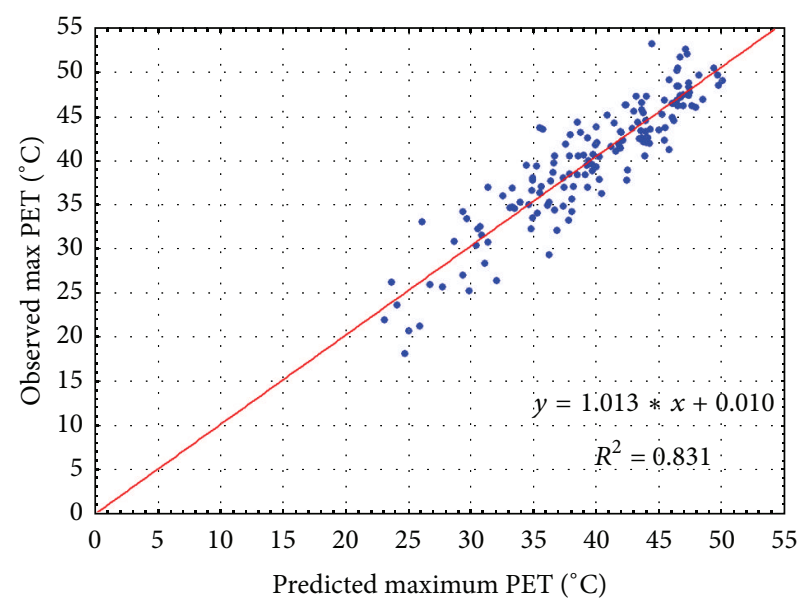

(b)

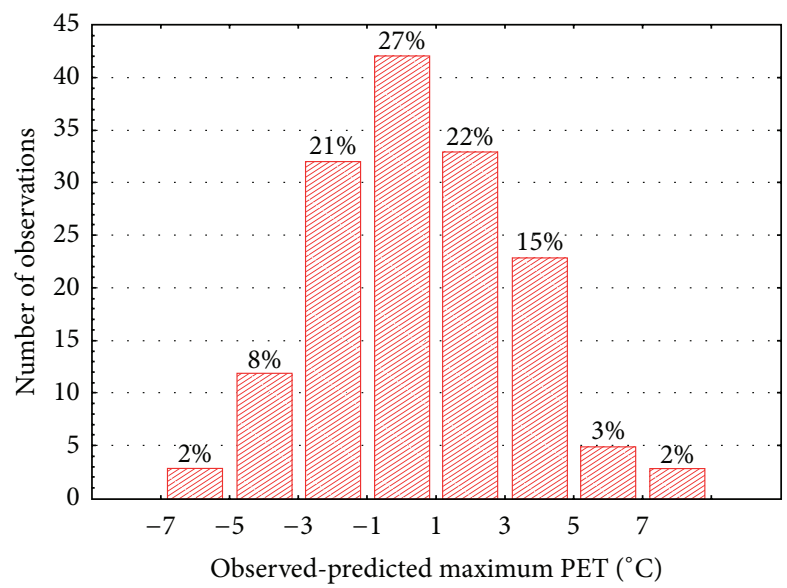

(d)

FIGURE 6: Observed versus predicted daily maximum PET values (a); scatter plot between observed versus predicted daily maximum PET values (b); observed minus predicted daily maximum PET values (c) and histogram with the absolute differences between the observed and the predicted daily maximum PET values (d). One day ahead prognosis. Warm period of 2011.

concerned, SI was found equal to $84.3 \%$, indicating that the fraction of correct predictions over total predictions is about $84.3 \%$.

The findings of the analysis during the warm period of the year revealed that the combination of the prognosis of the daily maximum and minimum PET values with the prognosis of the number of extreme heat stress hours simultaneously, one day ahead, gives the ability for a good monitoring of what is expected to happen during the next day.

3.2. Cold Period of the Year (October-April). Following the same reasoning, the prognostic ability of the developed ANN no. 2 model is presented. The ANN no. 2 model was appropriately trained in order to predict, for the cold period of the year, the daily maximum and minimum PET values, as well as the number of extreme cold stress hours during the next day.
TABLE 4: Statistical indices for the evaluation of the forecasting ability of the developed ANN no. 1 forecasting model to predict the number of hours during the day when PET $>41.0^{\circ} \mathrm{C}$ (extreme heat stress). One day ahead prognosis. Warm period of 2011.

\begin{tabular}{lcccc}
\hline & $\begin{array}{c}\text { TPR } \\
(\%)\end{array}$ & $\begin{array}{c}\text { FPR } \\
(\%)\end{array}$ & $\begin{array}{c}\text { FAR } \\
(\%)\end{array}$ & $\begin{array}{c}\text { SI } \\
(\%)\end{array}$ \\
\hline Day with maximum PET $>41.0^{\circ} \mathrm{C}$ & 85.9 & 4.0 & 4.3 & 90.8 \\
Day with extreme heat hours & 80.0 & 9.5 & 7.7 & 84.3 \\
\hline
\end{tabular}

Figure 9 depicts, for the cold period of the year, the observed versus the predicted daily maximum PET values (a), the scatter plot between the observed versus the predicted daily maximum PET values (b), the differences between the observed and the predicted daily maximum PET values (c), and the histogram with the distribution of the absolute differences between the observed and the predicted daily 


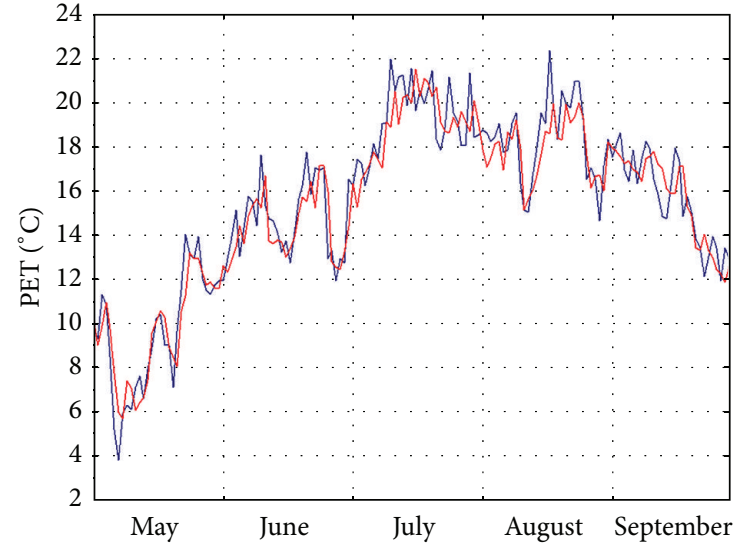

— Observed min PET
Predicted min PET

(a)

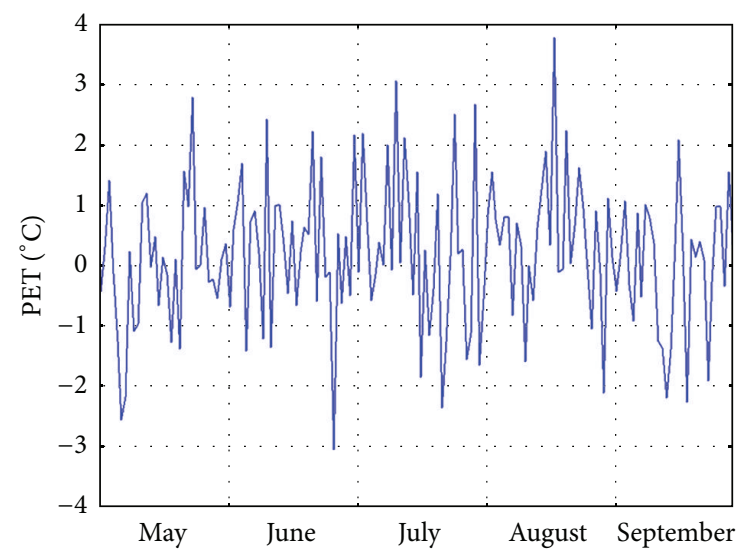

(c)

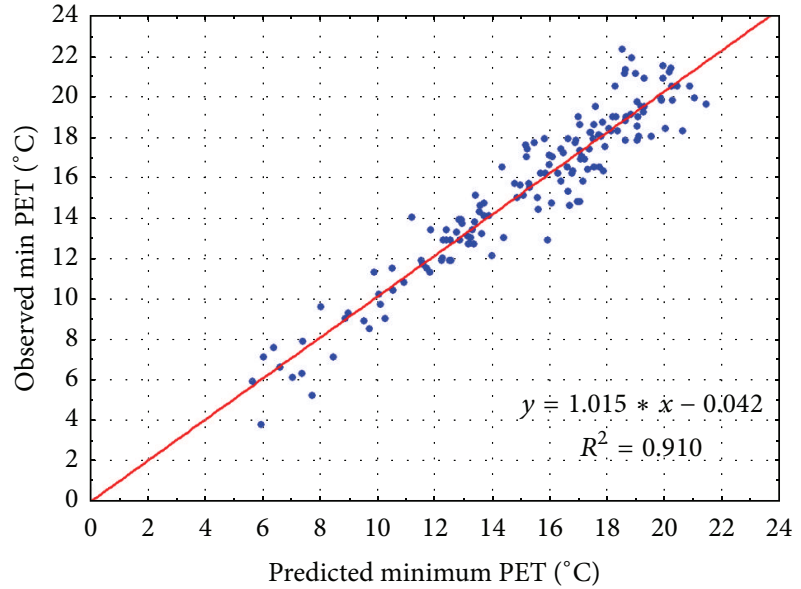

(b)

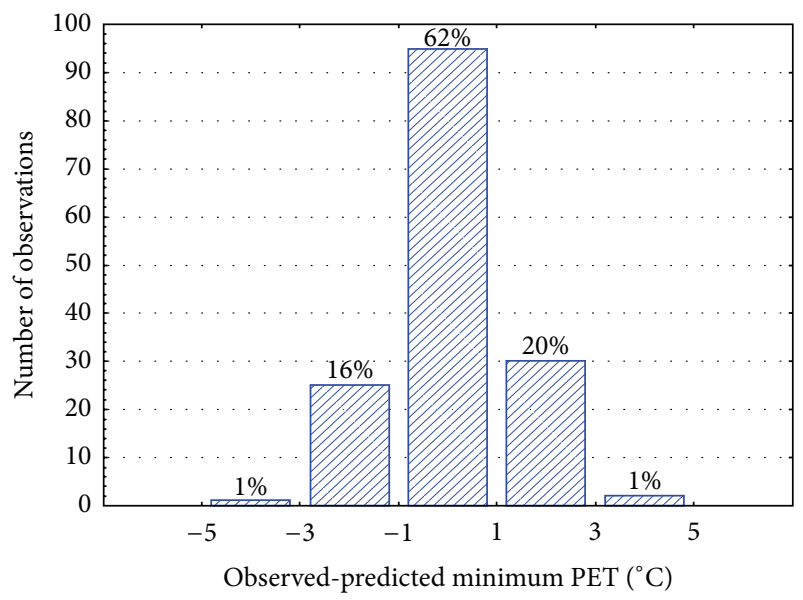

(d)

FIGURE 7: Observed versus predicted daily minimum PET values (a); scatter plot between observed versus predicted daily minimum PET values (b); observed minus predicted minimum daily PET values (c) and histogram with the absolute differences between the observed and the predicted minimum daily PET values (d). One day ahead prognosis. Warm period of 2011.

TABLE 5: Statistical indices for the evaluation of the forecasting ability of the developed ANN no. 2 forecasting model. One day ahead prognosis. Cold period of 2011.

\begin{tabular}{lcccc}
\hline & RMSE & MBE & $R^{2}$ & IA \\
\hline Maximum PET value $\left({ }^{\circ} \mathrm{C}\right)$ & $3.7^{\circ} \mathrm{C}$ & $-0.7^{\circ} \mathrm{C}$ & 0.819 & 0.943 \\
Minimum PET value $\left({ }^{\circ} \mathrm{C}\right)$ & $0.9^{\circ} \mathrm{C}$ & $+0.0^{\circ} \mathrm{C}$ & 0.940 & 0.984 \\
Hours with PET $<4.0^{\circ} \mathrm{C}$ & $2.3 \mathrm{hrs}$ & $+0.2 \mathrm{hrs}$ & 0.896 & 0.972 \\
\hline
\end{tabular}

maximum PET values (d). Figure 10 depicts the same as Figure 9, but with respect to daily minimum PET values. Table 5 presents the values of the statistical indices used for the evaluation of the forecasting ability of the developed ANN no. 2 model.

According to Figures 9 and 10 and Table 5, the developed ANN no. 2 prognostic model shows a very good forecasting ability. Concerning the prediction of the daily maximum PET value, during the cold period of the year, the coefficient of determination equals $R^{2}=0.819$, which means that the model is able to explain $81.9 \%$ of the variability of the daily maximum PET value, 24 hours ahead. Further, with respect to the prediction of the daily minimum PET value, $R^{2}$ equals to 0.940 , meaning that the model is able to explain $94.0 \%$ of the variability of the daily minimum PET value, 24 hours ahead. Also, $59.7 \%$ of the absolute differences between the observed and predicted daily maximum PET values range between $-3.0^{\circ} \mathrm{C}$ and $+3.0^{\circ} \mathrm{C}$, against $100.0 \%$ of the absolute differences between the observed and predicted daily minimum PET values. The same conclusions can be derived concerning the prognosis of the number of the hours during the next day with extreme cold stress $\left(\mathrm{PET}<4.0^{\circ} \mathrm{C}\right)$. Figure 11 presents the observed versus the predicted hours with PET $<4.0^{\circ} \mathrm{C}(\mathrm{a})$, the scatter plot between the observed and predicted hours with PET $<4.0^{\circ} \mathrm{C}(\mathrm{b})$, the differences between the observed and the predicted hours with $\mathrm{PET}<4.0^{\circ} \mathrm{C}$ (c), and the histogram with the distribution of the absolute differences 


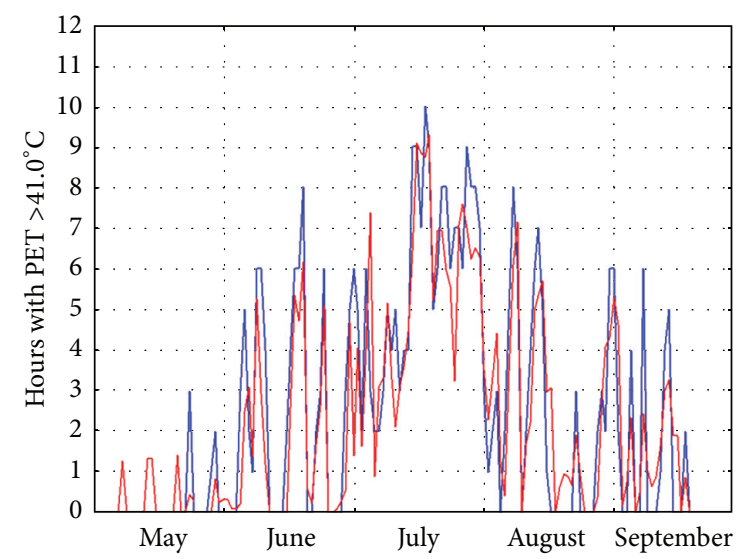

- Observed hours

- Predicted hours

(a)

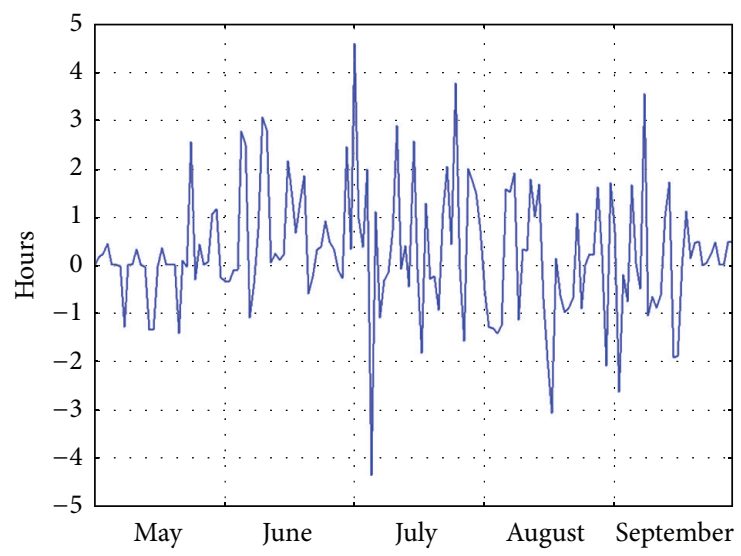

(c)

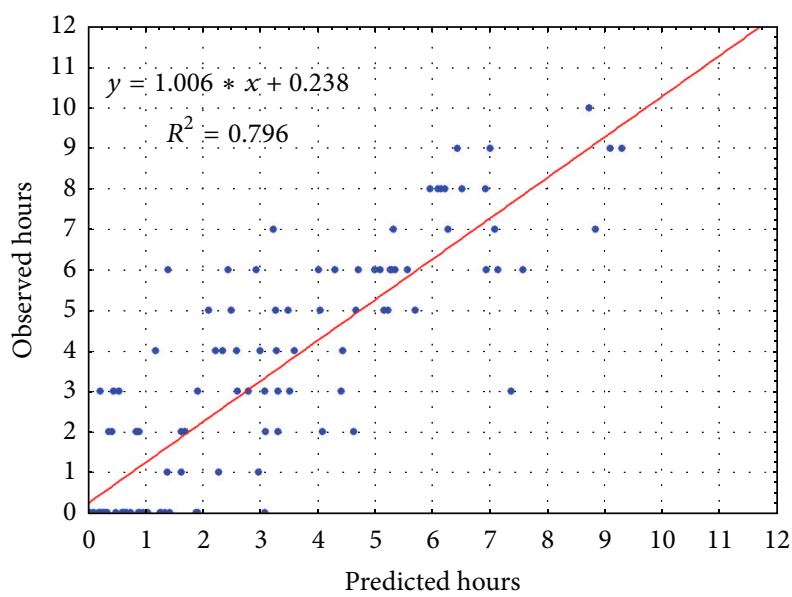

(b)

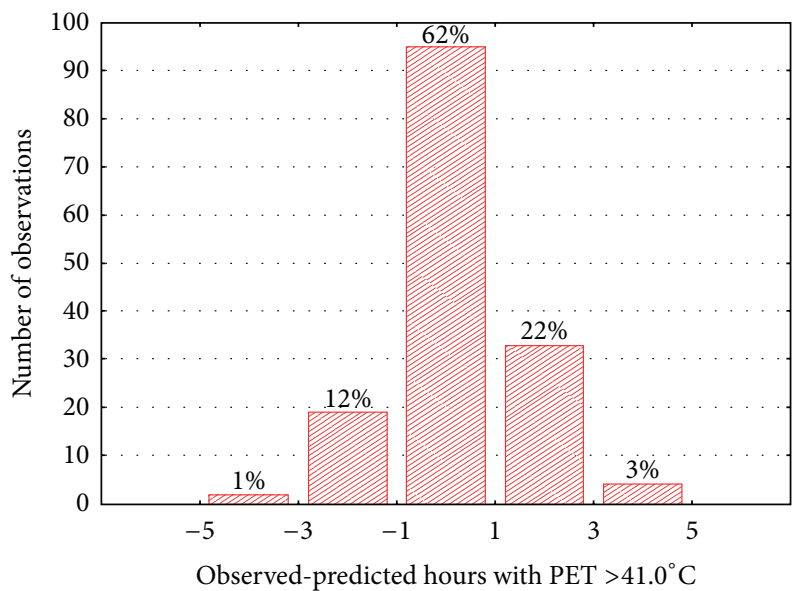

(d)

FIGURE 8: Observed versus predicted hours with PET $>41.0^{\circ} \mathrm{C}$ (a); scatter plot between the observed and predicted hours with $\mathrm{PET}>41.0^{\circ} \mathrm{C}$ (b); observed minus predicted hours with PET $>41.0^{\circ} \mathrm{C}$ (c) and histogram with the absolute differences between the observed and the predicted hours with $\mathrm{PET}>41.0^{\circ} \mathrm{C}(\mathrm{d})$. One day ahead prognosis. Warm period of 2011.

between the observed and the predicted hours with PET $<4.0^{\circ} \mathrm{C}(\mathrm{d})$. The coefficient of determination equals $R^{2}=$ 0.896, which means that the developed model is able to explain $89.6 \%$ of the variability of the hours with extreme cold stress, one day ahead. Further, $82.6 \%$ of the absolute differences between the observed and the predicted hours with $\mathrm{PET}<4.0^{\circ} \mathrm{C}$ range between -3.0 hours and +3.0 hours. All the aforementioned indicate that the developed ANN no. 2 prognostic model, after its appropriate training phase, presents a very satisfactory forecasting ability at a significant statistical level of $P<0.01$.

Table 6 presents the values of the statistical indices for the evaluation of the forecasting ability of the developed model ANN no. 2, in order to predict correctly the exceedances days, in other words, the days with minimum PET value less than $4.0^{\circ} \mathrm{C}$ (extreme cold stress hours). Concerning the ability of the model to forecast whether the next day is going
TABLE 6: Statistical indices for the evaluation of the forecasting ability of the developed ANN no. 2 forecasting model to predict the number of hours during the day when PET $<4.0^{\circ} \mathrm{C}$ (extreme cold stress). One day ahead prognosis. Cold period of 2011.

\begin{tabular}{lcccc}
\hline & $\begin{array}{c}\text { TPR } \\
(\%)\end{array}$ & $\begin{array}{c}\text { FPR } \\
(\%)\end{array}$ & $\begin{array}{c}\text { FAR } \\
(\%)\end{array}$ & $\begin{array}{c}\text { SI } \\
(\%)\end{array}$ \\
\hline Day with maximum PET $<4.0^{\circ} \mathrm{C}$ & 92.8 & 7.9 & 3.8 & 92.5 \\
Day with extreme cold hours & 98.6 & 31.7 & 12.8 & 89.1 \\
\hline
\end{tabular}

to be a day with extreme cold stress (exceedance day) and according to Table 6 , the true predicted rate is TPR $=92.8 \%$, which indicates that the fraction of the correct predictions over total exceedances is forecasted by the model at a rate of $92.8 \%$. Also, FPR $=7.9 \%$, which means that the fraction of false predictions over total nonexceedances is quite small. 


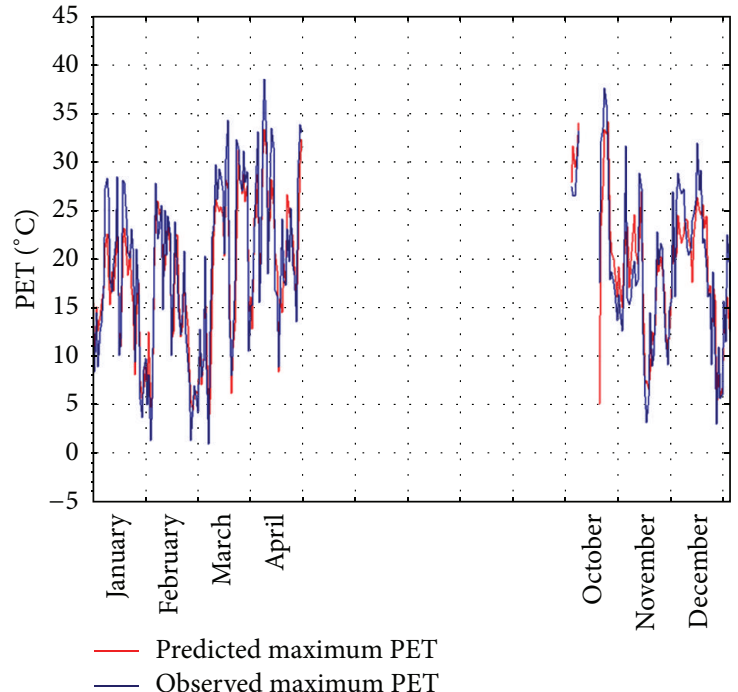

(a)

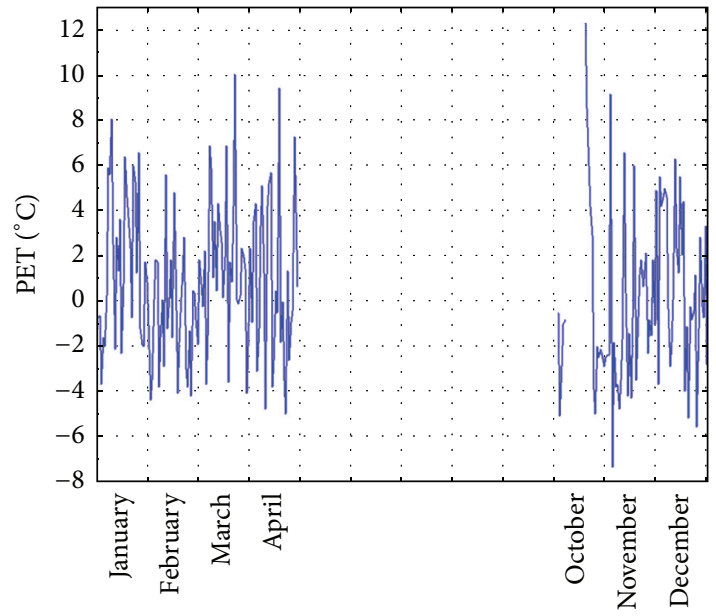

(c)

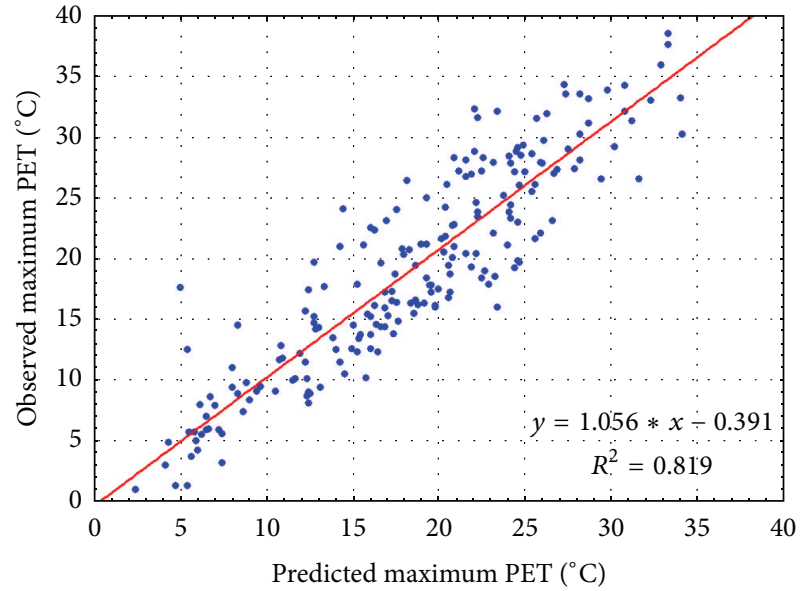

(b)

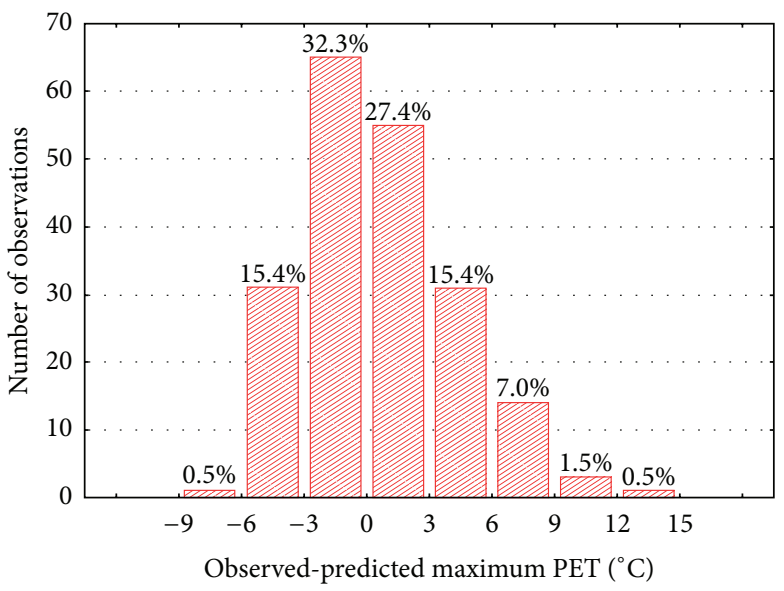

(d)

FIGURE 9: Observed versus predicted daily maximum PET values (a); scatter plot between observed versus predicted daily maximum PET values (b); observed minus predicted daily maximum PET values (c) and histogram with the absolute differences between the observed and the predicted daily maximum PET values (d). One day ahead prognosis. Cold period of 2011.

Furthermore, FAR $=3.8 \%$, meaning that the fraction of false predictions over total exceedances is very small. Finally, SI $=92.5 \%$, which indicates that the fraction of correct predictions over total predictions is about $92.5 \%$. In other words, the developed ANN no. 2 model is able to forecast at a rate of $92.5 \%$ whether the next day will be an exceedance day or not. Regarding the hours with extreme cold stress (PET < $4.0^{\circ} \mathrm{C}$ ) for the next day, SI equals to $89.1 \%$, which indicates that the fraction of correct predictions over total predictions is about $89.1 \%$.

From the performed analysis during the cold period of the year, it is concluded that the combination of the prognosis of the daily maximum and minimum PET values with the prognosis of the number of the extreme cold stress hours simultaneously, one day ahead, gives the ability for a good monitoring of what is expected to happen during the next day.

\section{Conclusions}

The main objective of this work was to develop prognostic models, using the artificial neural networks topology, in order to forecast 24 hours ahead the biometeorological human conditions for both the warm and the cold period of the year. For that purpose, the hourly values of the well-known human thermal index PET were calculated for the time period from 15/06/2005 till 31/12/2011 in an open space area of Galatsi, which is located inside the urban environment of the capital city Athens, Greece. The appropriate calculation of the hourly PET values was carried out using the RayMan model.

Statistical treatment of the available data showed that during the calendar year, both extreme heat and cold stress hours appear. During the warm period of the year, $10.0 \%$ of the examined hours present extreme heat stress (PET > $41.0^{\circ} \mathrm{C}$ ). Respectively, $22.8 \%$ of the hours during the cold 


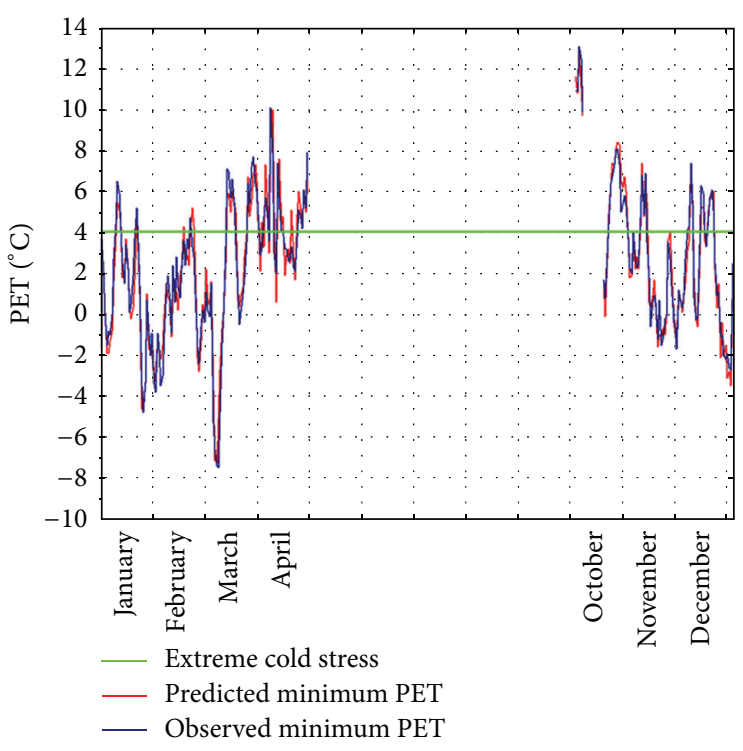

(a)

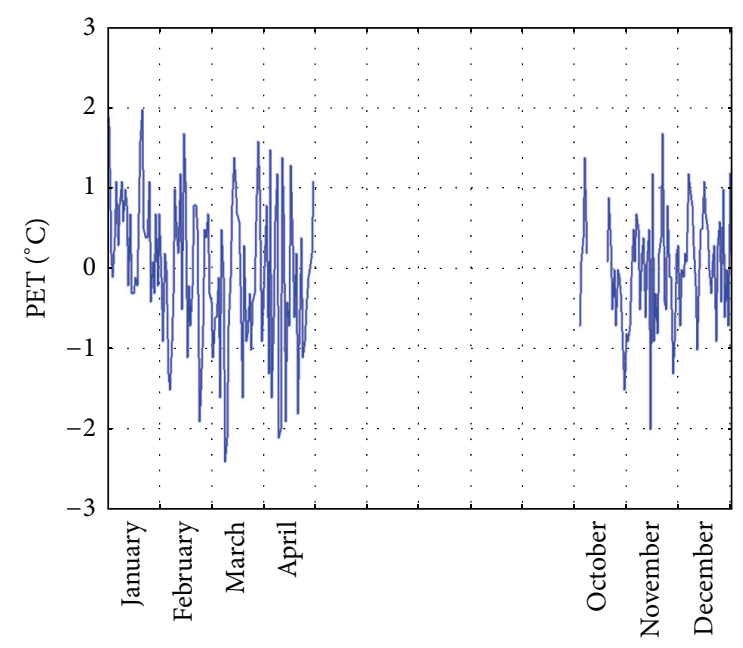

(c)

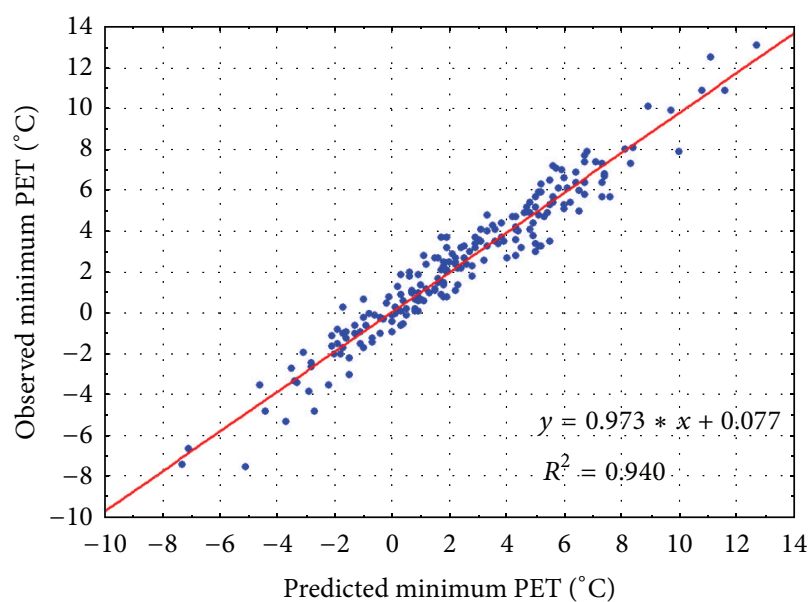

(b)

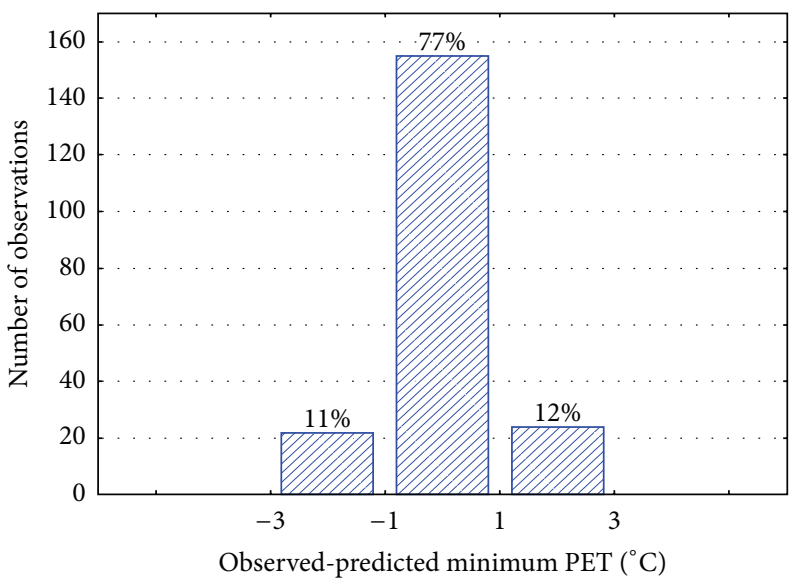

(d)

FIGURE 10: Observed versus predicted daily minimum PET values (a); scatter plot between observed versus predicted daily minimum PET values (b); observed minus predicted daily minimum PET values (c) and histogram with the absolute differences between the observed and the predicted daily minimum PET values (d). One day ahead prognosis. Cold period of 2011.

period of the year present extreme cold stress $\left(\mathrm{PET}<4.0^{\circ} \mathrm{C}\right)$. Finally, $81.8 \%$ of the hours during the calendar year present a comfort human thermal sensation $\left(18.0^{\circ} \mathrm{C}<\mathrm{PET}<29.0^{\circ} \mathrm{C}\right)$, indicating that, in general, the bioclimatic conditions in the examined monitoring site are healthy comfort conditions for a humans.

As far as the prognostic ability of the two developed models (ANN no. 1 and ANN no. 2) is concerned, the values of appropriate statistical evaluation indices indicate a very satisfactory forecasting ability at a significant statistical level of $P<0.01$. The developed ANN models show a satisfactory and sufficient prognostic ability in order to forecast the daily maximum and minimum PET value, as well as the number of extreme heat or cold stress hours for the next day. The innovation of this work consists of the reasons listed below. (a) The ANNs modeling is applied instead of traditional statistical modeling.

(b) The biometeorological conditions were estimated applying the RayMan model and using the PET index, a modern index which can describe very precisely the human thermal comfort-discomfort conditions.

(c) The developed forecasting models seem to be able to forecast 24 hours ahead not only the human thermal comfort-discomfort levels but also the persistence of extreme heat or cold stress, depending on the period of the year. Thus, in an operational form, it will be a very important tool for the state to take the appropriate measures to avoid negative results 


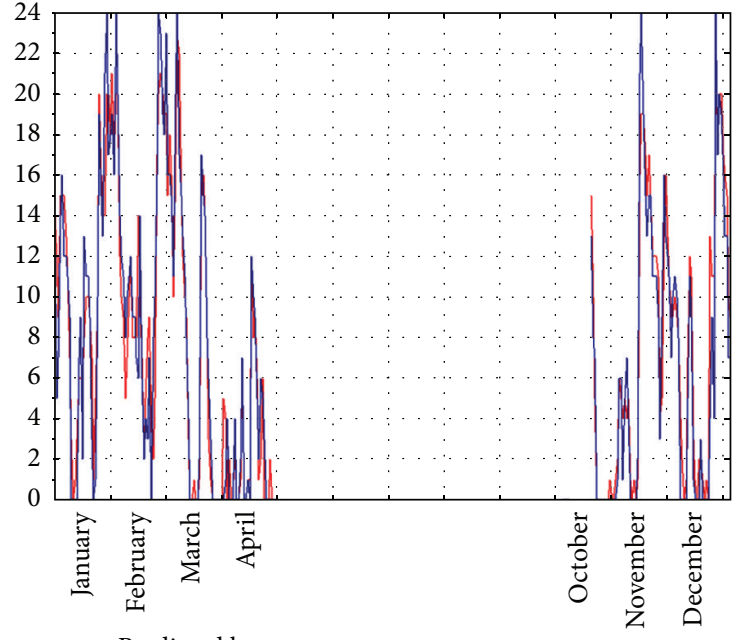

— Predicted hours

— Observed hours

(a)

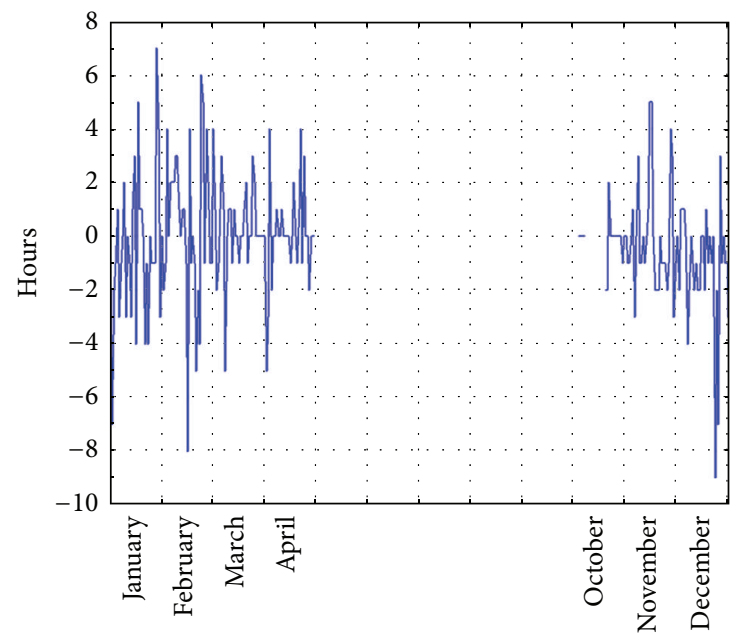

(c)

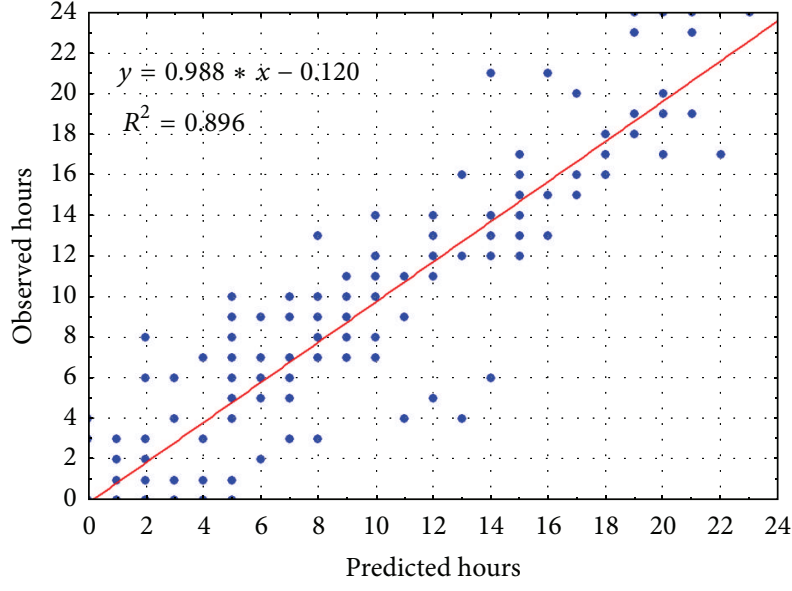

(b)

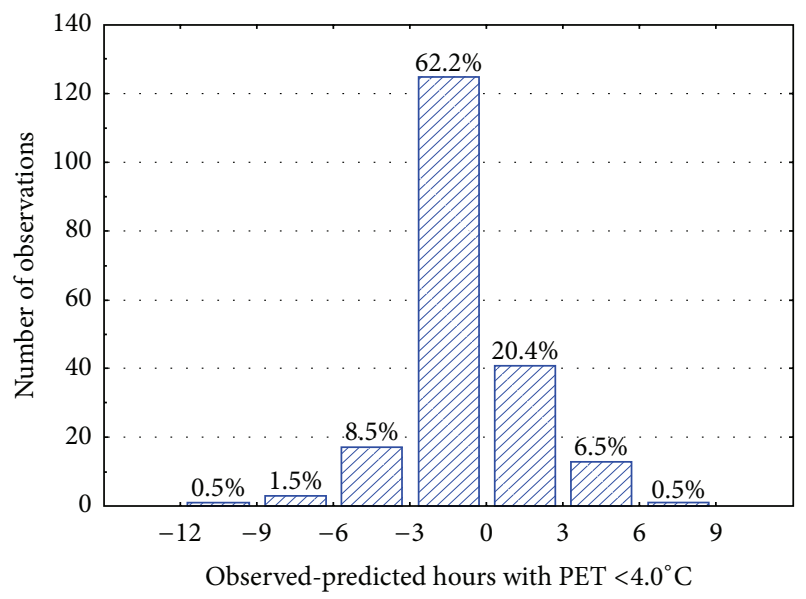

(d)

FIGURE 11: Observed versus predicted hours with $\mathrm{PET}<4.0^{\circ} \mathrm{C}(\mathrm{a})$; scatter plot between the observed and predicted hours with $\mathrm{PET}<4.0^{\circ} \mathrm{C}(\mathrm{b})$; observed minus predicted hours with PET $<4.0^{\circ} \mathrm{C}(\mathrm{c})$ and histogram with the absolute differences between the observed and the predicted hours with $\mathrm{PET}<4.0^{\circ} \mathrm{C}(\mathrm{d})$. One day ahead prognosis. Cold period of 2011.

for the population due to extreme meteorological circumstances.

(d) Finally, the developed ANN models (ANN no. 1 and ANN no. 2) are able to forecast the extreme (maximum and minimum) daily values of PET, as well as the persistence of the phenomenon simultaneously, providing real time prognosis.

According to authors' opinion, furthermore investigation is necessary in order to increase the prognostic ability of the proposed ANN models, as well as to extend the prediction time at 48 or 72 hours ahead. In that way, a forecasting and a protection monitoring network for the public health would be developed. Also, the state would obtain prior warning of extreme energy demand due to extreme heat waves within the warm period of the year.

\section{References}

[1] I. Tselepidaki, M. Santamouris, C. Moustris, and G. Poulopoulou, "Analysis of the summer discomfort index in Athens, Greece, for cooling purposes," Energy and Buildings, vol. 18, no. 1, pp. 51-56, 1992.

[2] M. Santamouris, "Natural cooling techniques," in Proceedings of the Passive Cooling Conference, EEC, DG, Ispra, Italy, 1990.

[3] M. Caudill and C. Butler, Understanding Neural Networks, MIT Press, Cambridge, Mass, USA, 1992.

[4] B. Givoni, Climatic Considerations in Building and Urban Design, Van Nostrond Reinholds, New York, NY, USA, 1998.

[5] S. Becker, O. Potchter, and Y. Yaakov, "Calculated and observed human thermal sensation in an extremely hot and dry climate," Energy and Buildings, vol. 35, no. 8, pp. 747-756, 2003.

[6] S. Conti, P. Meli, G. Minelli et al., "Epidemiologic study of mortality during the Summer 2003 heat wave in Italy," Environmental Research, vol. 98, no. 3, pp. 390-399, 2005. 
[7] A. Matzarakis, H. Mayer, and M. G. Iziomon, "Applications of a universal thermal index: physiological equivalent temperature," International Journal of Biometeorology, vol. 43, no. 2, pp. 76-84, 1999.

[8] I. Charalampopoulos, I. Tsiros, A. Chronopoulou-Sereli, and A. Matzarakis, "Analysis of thermal bioclimate in various urban configurations in Athens, Greece," Urban Ecosystems, vol. 16, no. 2, pp. 217-233, 2013.

[9] M. Bruse and H. Fleer, "Simulating surface-plant-air interactions inside urban environments with a three dimensional numerical model," Environmental Modelling \& Software, vol. 13, no. 3-4, pp. 373-384, 1998.

[10] A. Matzarakis, F. Rutz, and H. Mayer, "Modelling radiation fluxes in simple and complex environments-application of the RayMan model," International Journal of Biometeorology, vol. 51, no. 4, pp. 323-334, 2007.

[11] R. Emmanuel, H. Rosenlund, and E. Johansson, "Urban shading-a design option for the tropics? A study in Colombo, Sri Lanka," International Journal of Climatology, vol. 27, no. 14, pp. 1995-2004, 2007.

[12] A. Matzarakis, M. De Rocco, and G. Najjar, “Thermal bioclimate in Strasbourg-the 2003 heat wave," Theoretical and Applied Climatology, vol. 98, no. 3-4, pp. 209-220, 2009.

[13] S. Muthers, A. Matzarakis, and E. Koch, "Summer climate and mortality in Vienna-a human-biometeorological approach of heat-related mortality during the heat waves in 2003," Wiener Klinische Wochenschrift, vol. 122, no. 17-18, pp. 525-531, 2010.

[14] F. Benvenuto and A. Marani, "Neural networks for environmental problems: data quality control and air pollution nowcasting," Global Nest Journal, vol. 2, no. 3, pp. 281-292, 2000.

[15] D. Melas, I. Kioutsioukis, and I. C. Ziomas, "Neural network model for predicting peak photochemical pollutant levels," Journal of the Air \& Waste Management Association, vol. 50, no. 4, pp. 495-501, 2000.

[16] I. X. Tsiros and I. F. Dimopoulos, "A preliminary study of the application of some predictive modeling techniques to assess atmospheric mercury emissions from terrestrial surfaces," Journal of Environmental Science and Health, Part A, vol. 38, no. 11, pp. 2495-2508, 2003.

[17] I. F. Dimopoulos, I. X. Tsiros, K. Serelis, and A. Chronopoulou, "Combining neural network models to predict spatial patterns of airborne pollutant accumulation in soils around an industrial point emission source," Journal of the Air \& Waste Management Association, vol. 54, no. 12, pp. 1506-1515, 2004.

[18] P. Perez and J. Reyes, "An integrated neural network model for PM10 forecasting," Atmospheric Environment, vol. 40, no. 16, pp. 2845-2851, 2006.

[19] D. Wang and W.-Z. Lu, "Forecasting of ozone level in time series using MLP model with a novel hybrid training algorithm," Atmospheric Environment, vol. 40, no. 5, pp. 913-924, 2006.

[20] K. I. Chronopoulos, I. X. Tsiros, I. F. Dimopoulos, and N. Alvertos, "An application of artificial neural network models to estimate air temperature data in areas with sparse network of meteorological stations," Journal of Environmental Science and Health, Part A, vol. 43, no. 14, pp. 1752-1757, 2008.

[21] J. A. Sánchez Mesa, C. Galán, and C. Hervás, "The use of discriminant analysis and neural networks to forecast the severity of the Poaceae pollen season in a region with a typical Mediterranean climate," International Journal of Biometeorology, vol. 49, no. 6, pp. 355-362, 2005.
[22] A. Grinn-Gofroń and A. Strzelczak, "Artificial neural network models of relationships between Alternaria spores and meteorological factors in Szczecin (Poland)," International Journal of Biometeorology, vol. 52, no. 8, pp. 859-868, 2008.

[23] G. Mihalakakou, M. Santamouris, N. Papanikolaou, C. Cartalis, and A. Tsangrassoulis, "Simulation of the urban heat island phenomenon in Mediterranean climates," Pure and Applied Geophysics, vol. 161, no. 2, pp. 429-451, 2004.

[24] L. Gao and H. Bai, "The prediction of PMV index based on neural networks," in Proceedings of the International Conference on Energy and the Environment, vol. 2, pp. 1306-1309, December 2003.

[25] A. S. W. Wong, Y. Li, P. K. W. Yeung, and P. W. H. Lee, "Neural network predictions of human psychological perceptions of clothing sensory comfort," Textile Research Journal, vol. 73, no. 1, pp. 31-37, 2003.

[26] Y.-Z. Ji, G.-B. Tu, and X.-J. Wang, "Feasibility of artificial neural network on thermal comfort research," Journal of Tianjin University Science and Technology, vol. 37, no. 4, pp. 331-335, 2004.

[27] S. Atthajariyakul and T. Leephakpreeda, "Neural computing thermal comfort index for HVAC systems," Energy Conversion and Management, vol. 46, no. 15-16, pp. 2553-2565, 2005.

[28] G. Liu, J. Zhou, G. Wang, S. Hu, and R. Liu, "Human thermal comfort assessment model under lower-pressure environment based on BP network," in Proceedings of the International Conference on Information Engineering and Computer Science (ICIECS '09), Wuhan, China, December 2009.

[29] K. P. Moustris, I. C. Ziomas, and A. G. Paliatsos, "24 hours in advance forecasting of thermal comfort-discomfort levels during the hot period of the year at representative locations of Athens city, Greece," Fresenius Environmental Bulletin, vol. 18, no. 5, pp. 601-608, 2009.

[30] K. P. Moustris, I. X. Tsiros, I. C. Ziomas, and A. G. Paliatsos, "Artificial neural network models as a useful tool to forecast human thermal comfort using microclimatic and bioclimatic data in the great Athens area (Greece)," Journal of Environmental Science and Health, Part A, vol. 45, no. 4, pp. 447-453, 2010.

[31] P. A. Vouterakos, K. P. Moustris, A. Bartzokas, I. C. Ziomas, P. T. Nastos, and A. G. Paliatsos, "Forecasting the discomfort levels within the greater Athens area, Greece using artificial neural networks and multiple criteria analysis," Theoretical and Applied Climatology, vol. 110, no. 3, pp. 329-343, 2012.

[32] B. D. Katsoulis and G. A. Theoharatos, "Indications of the urban heat island in Athens, Greece," Journal of Climate \& Applied Meteorology, vol. 24, no. 12, pp. 1296-1302, 1985.

[33] I. Livada, M. Santamouris, K. Niachou, N. Papanikolaou, and G. Mihalakakou, "Determination of places in the great Athens area where the heat island effect is observed," Theoretical and Applied Climatology, vol. 71, no. 3-4, pp. 219-230, 2002.

[34] G. Mihalakakou, H. A. Flocas, M. Santamouris, and C. G. Helmis, "Application of neural networks to the simulation of the heat island over Athens, Greece, using synoptic types as a predictor," Journal of Applied Meteorology, vol. 41, no. 5, pp. 519527, 2002.

[35] M. Santamouris, K. Paraponiaris, and G. Mihalakakou, "Estimating the ecological footprint of the heat island effect over Athens, Greece," in Proceedings of the International Conference Passive and Low Energy Cooling for the Built Environment, pp. 113-116, Santorini, Greece, 2005.

[36] K. P. Moustris, G. T. Proias, I. K. Larissi, P. T. Nastos, and A. G. Paliatsos, "Bioclimatic and air quality conditions in the greater 
Athens area, Greece, during the warm period of the year: trends, variability and persistence," Fresenius Environmental Bulletin, vol. 21, no. 8, pp. 2368-2374, 2012.

[37] “The Hydrological Observatory of Athens," 2012, http://hoa .ntua.gr/.

[38] P. T. Nastos and A. Matzarakis, "The effect of air temperature and human thermal indices on mortality in Athens, Greece," Theoretical and Applied Climatology, vol. 108, no. 3-4, pp. 591599, 2012.

[39] H. Mayer and P. Höppe, "Thermal comfort of man in different urban environments," Theoretical and Applied Climatology, vol. 38, no. 1, pp. 43-49, 1987.

[40] P. Höppe, "The physiological equivalent temperature-a universal index for the biometeorological assessment of the thermal environment," International Journal of Biometeorology, vol. 43, no. 2, pp. 71-75, 1999.

[41] A. Matzarakis and H. Mayer, "Another kind of environmental stress: thermal stress," WMO Newsletter, vol. 18, pp. 7-10, 1996.

[42] M. A. Nelson, M. D. Williams, D. Zajic, E. R. Pardyjak, and M. J. Brown, "Evaluation of an urban vegetative canopy scheme and impact on plume dispersion," in Proceedings of the 89th American Meteorological Society Annual Meeting, Phoenix, Ariz, USA, 2009.

[43] R. W. Macdonald, "Modelling the mean velocity profile in the urban canopy layer," Boundary-Layer Meteorology, vol. 97, no. 1, pp. 25-45, 2000.

[44] "Estimate wind speed at a height above your measurement height," 2013, http://www.baranidesign.com/wind-height/.

[45] W. S. McCulloch and W. Pitts, "A logical calculus of the ideas immanent in nervous activity," The Bulletin of Mathematical Biophysics, vol. 5, no. 4, pp. 115-133, 1943.

[46] R. Hect-Nielsen, Neurocomputing, Addison-Wesley, Reading, Mass, USA, 1990.

[47] P. Viotti, G. Liuti, and P. Di Genova, "Atmospheric urban pollution: applications of an Artificial Neural Network (ANN) to the city of Perugia," Ecological Modelling, vol. 148, no. 1, pp. 27-46, 2002.

[48] R. Hect-Nielsen, Neurocomputing, Addison-Wesley, Reading, Mass, USA, 1991.

[49] G. Corani and S. Barazzeta, "First results in the prediction of particulate matter in the Milan area," in Proceedings of the 9th International Conference on Harmonisation within Atmospheric Dispersion Modelling for Regulatory Purposes, vol. 1, pp. 365369, Garmisch-Partenkirchen, Germany, 2004.

[50] H. A. Panofsky and G. W. Brier, Some Applications of Statistics to Meteorology, Pennsylvania State University, University Park, Pa, USA, 1968.

[51] Y. P. Singh and B. Badruddin, "Statistical considerations in superposed epoch analysis and its applications in space research," Journal of Atmospheric and Solar, vol. 68, no. 7, pp. 803-813, 2006.

[52] D. W. Zimmerman, "Correcting two-sample $z$ and $t$ tests for correlation: an alternative to one-sample tests on difference scores," Psicológica, vol. 33, pp. 391-418, 2012.

[53] G. Spellman, "An application of artificial neural networks to the prediction of surface ozone concentrations in the United Kingdom," Applied Geography, vol. 19, no. 2, pp. 123-136, 1999.

[54] A. Elkamel, S. Abdul-Wahab, W. Bouhamra, and E. Alper, "Measurement and prediction of ozone levels around a heavily industrialized area: a neural network approach," Advances in Environmental Research, vol. 5, no. 1, pp. 47-59, 2001.
[55] R. S. Ettouney, F. S. Mjalli, J. G. Zaki, M. A. El-Rifai, and H. M. Ettouney, "Forecasting of ozone pollution using artificial neural networks," Management of Environmental Quality, vol. 20, no. 6, pp. 668-683, 2009.

[56] A. Mahapatra, "Prediction of daily ground-level ozone concentration maxima over New Delhi," Environmental Monitoring and Assessment, vol. 170, no. 1-4, pp. 159-170, 2010.

[57] M. Kolehmainen, H. Martikainen, and J. Ruuskanen, "Neural networks and periodic components used in air quality forecasting," Atmospheric Environment, vol. 35, no. 5, pp. 815-825, 2001.

[58] K. P. Moustris, I. C. Ziomas, and A. G. Paliatsos, "3-day-ahead forecasting of regional pollution index for the pollutants $\mathrm{NO}_{2}$, $\mathrm{CO}, \mathrm{SO}_{2}$, and $\mathrm{O}_{3}$ using artificial neural networks in Athens, Greece," Water, Air, \& Soil Pollution, vol. 209, no. 1-4, pp. 2943, 2010. 

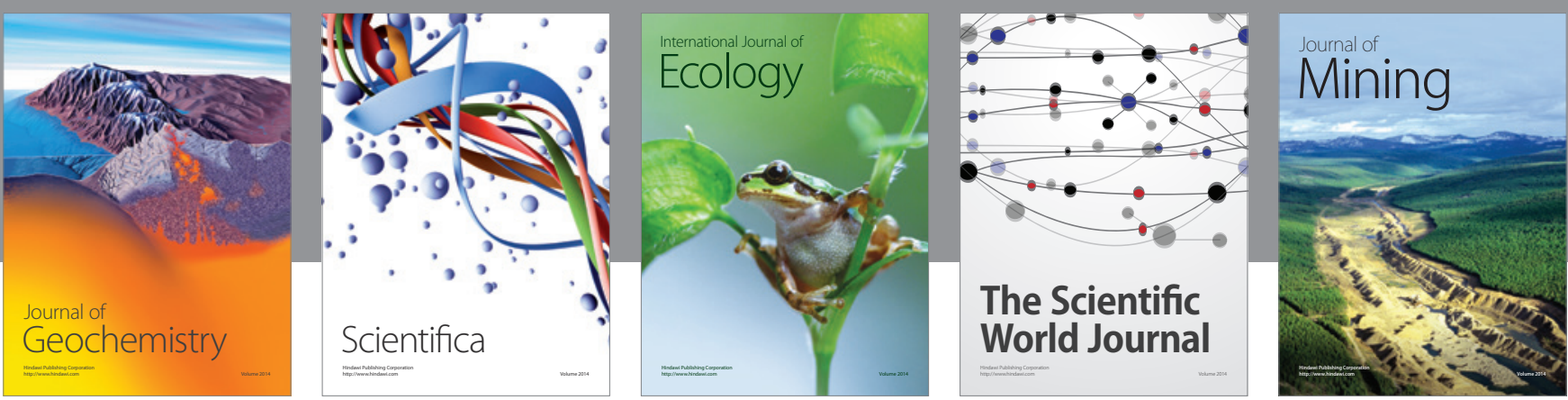

The Scientific World Journal
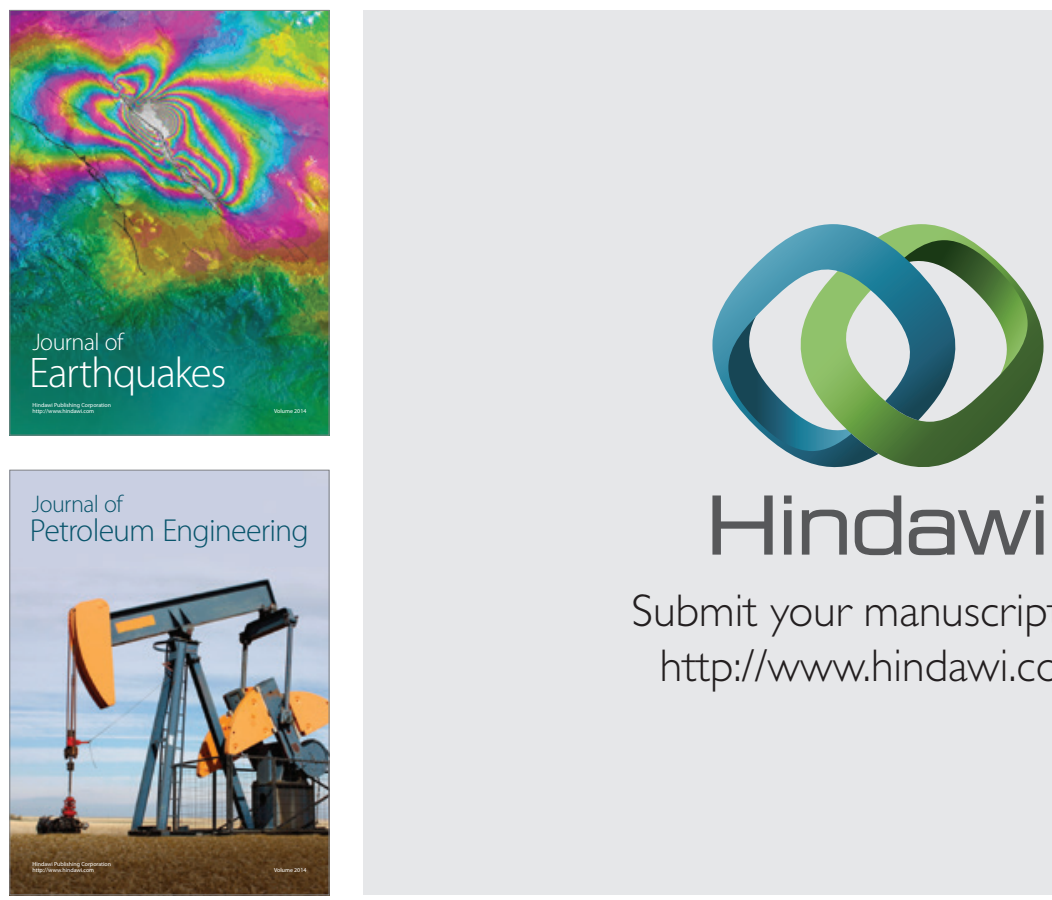

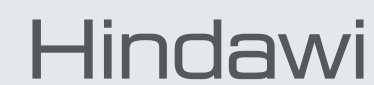

Submit your manuscripts at

http://www.hindawi.com
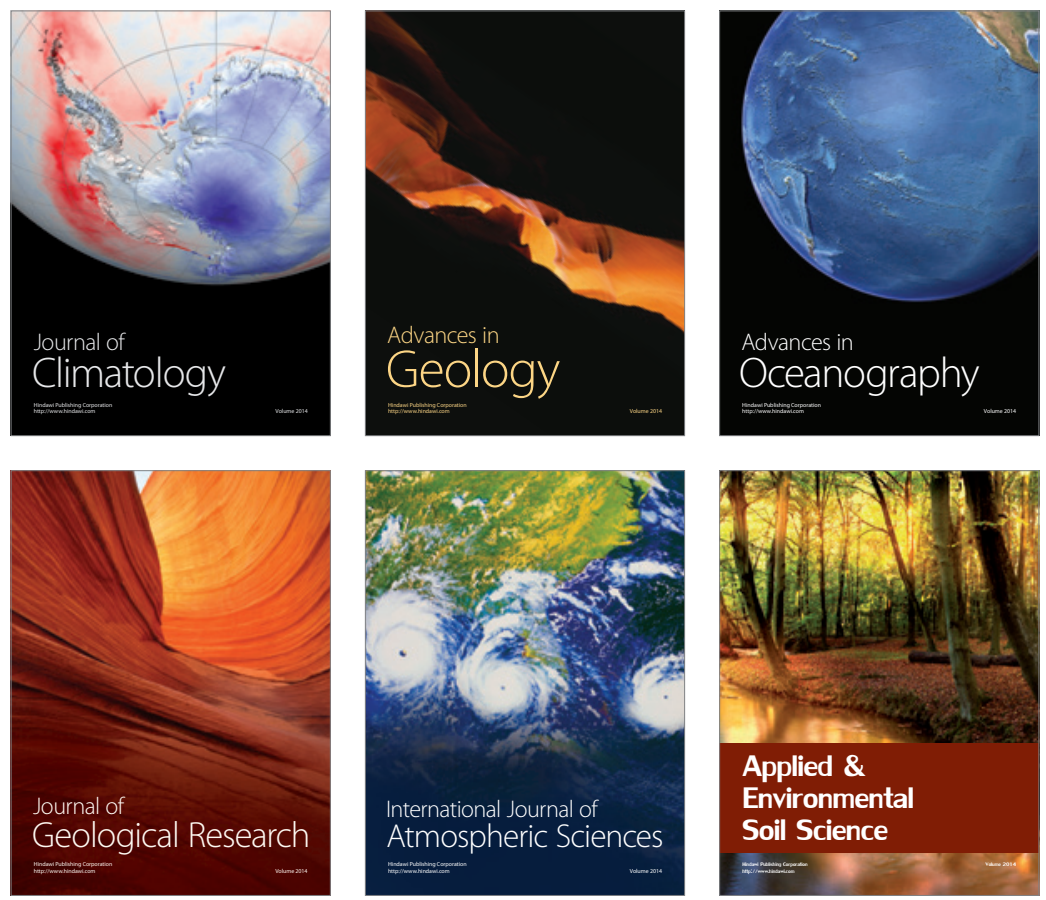
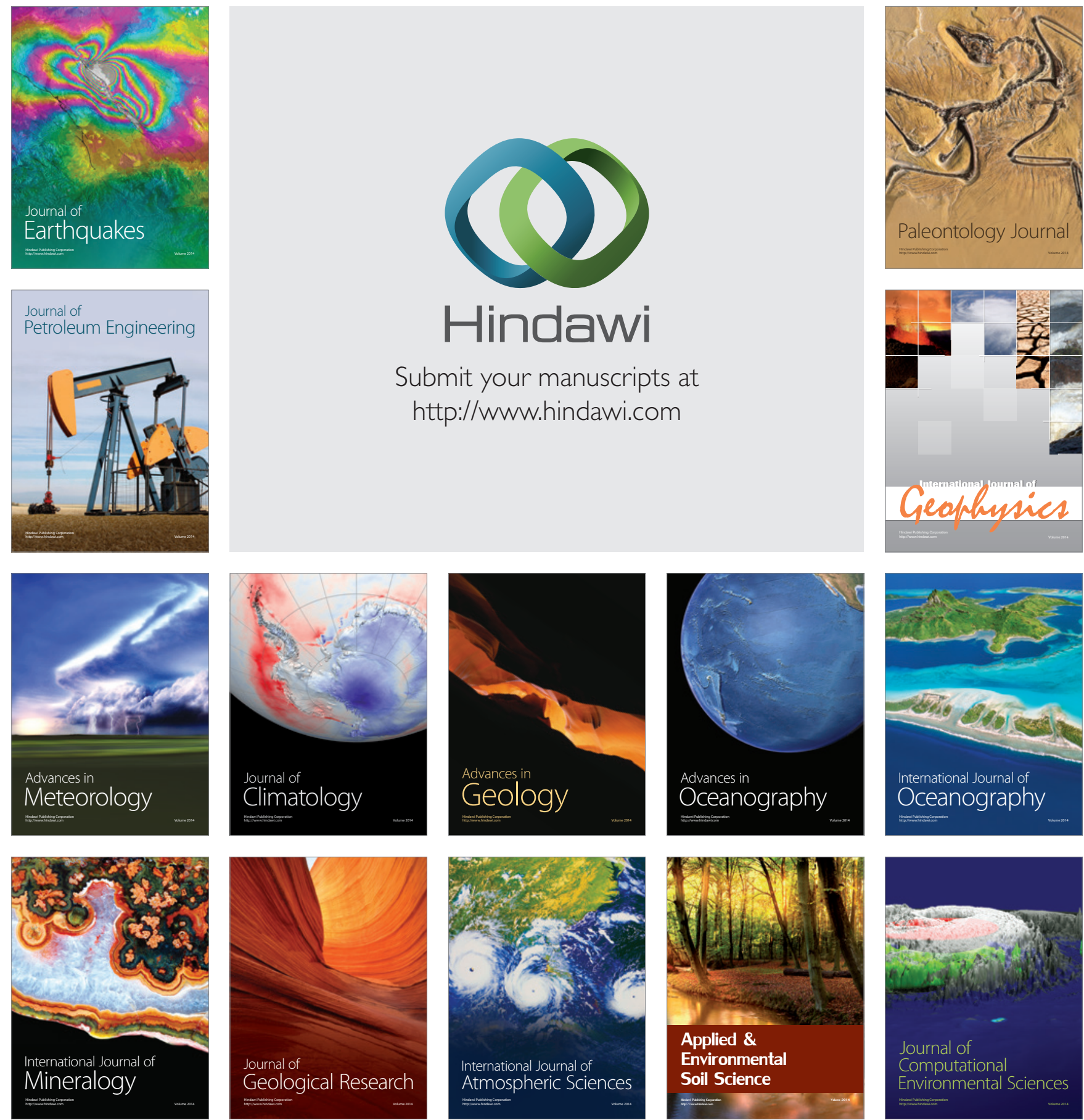